\section{$9 / \lambda^{4^{899}}$ \\ SANDIA REPORT}

SAND89-0567 - UC-400

Unlimited Release

Printed August 1989

\title{
Magma Energy Extraction Annual Report for FY88
}

James C. Dunn, Editor

\section{Prepared by}

Sandia National Laboratories

Albuquerque, New Mexico 87185 and Livermore, California 94550

for the United States Department of Energy

under Contract DE-AC04-76DP00789

\section{DO NOT MICROFLLLi COVER}

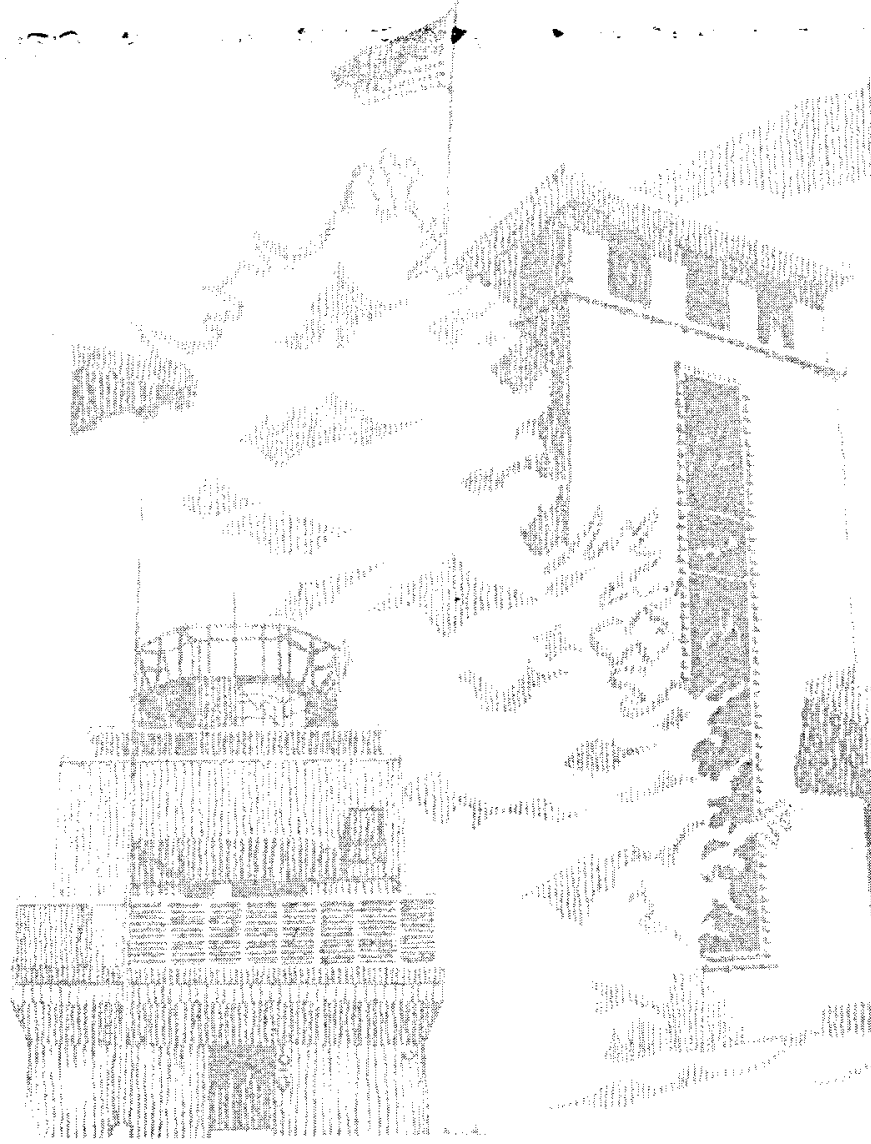




\section{DISCLAIMER}

This report was prepared as an account of work sponsored by an agency of the United States Government. Neither the United States Government nor any agency Thereof, nor any of their employees, makes any warranty, express or implied, or assumes any legal liability or responsibility for the accuracy, completeness, or usefulness of any information, apparatus, product, or process disclosed, or represents that its use would not infringe privately owned rights. Reference herein to any specific commercial product, process, or service by trade name, trademark, manufacturer, or otherwise does not necessarily constitute or imply its endorsement, recommendation, or favoring by the United States Government or any agency thereof. The views and opinions of authors expressed herein do not necessarily state or reflect those of the United States Government or any agency thereof. 


\section{DISCLAIMER}

Portions of this document may be illegible in electronic image products. Images are produced from the best available original document. 
Issued by Sandia National Laboratories, operated for the United States Department of Energy by Sandia Corporation.

NOTICE: This report was prepared as an account of work sponsored by an agency of the United States Government. Neither the United States Government nor any agency thereof, nor any of their employees, nor any of their contractors, subcontractors, or their employees, makes any warranty, express or implied, or assumes any legal liability or responsibility for the accuracy, completeness, or usefulness of any information, apparatus, product, or process disclosed, or represents that its use would not infringe privately owned rights. Reference herein to any specific commercial product, process, or service by trade name, trademark, manufacturer, or otherwise, does not necessarily constitute or imply its endorsement, recommendation, or favoring by the United States Government, any agency thereof or any of their contractors or subcontractors. The views and opinions expressed herein do not necessarily state or reflect those of the United States Government, any agency thereof or any of their contractors.

Printed in the United States of America. This report has been reproduced directly from the best available copy.

Available to DOE and DOE contractors from

Office of Scientific and Technical Information

PO Box 62

Oak Ridge, TN 37831

Prices available from (615) 576-8401, FTS 626-8401

Available to the public from

National Technical Information Service

US Department of Commerce

5285 Port Royal Rd

Springfield, VA 22161

NTIS price codes

Printed copy: A04

Microfiche copy: A01

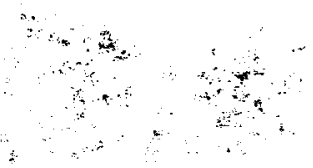


MAGMA ENERGY EXTRACTION

ANNUAL REPORT FOR FY88

EDITED BY JAMES C. DUNN

SANDIA NATIONAL LABORATORIES

ALBUQUERQUE, NEW MEXICO 87185

\section{DISCLAIMER}

This report was prepared as an account of work sponsored by an agency of the United States Government. Neither the United States Government nor any agency thereof, nor any of their employees, makes any warranty, express or implied, or assumes any legal liability or responsibility for the accuracy, completeness, or usefulness of any information, apparatus, product, or process disclosed, or represionts that its use would not infringe privately owned rights. Reference herein to any specific commercial product, process, or service by trade name, trademark, manufacturer, or otherwise does not necessarily constitute or imply its endorsement, recommendation, or favoring by the United States Government or any agency thereof. The views and opinions of authors expressed herein do not necessarily state or reflect those of the United States Government or any agency thereof. 
EXECUTIVE SUMMARY . . . . . . . . . . . . . . . . i

1.0 INTRODUCTION ................... 1

1.1 Background . . . . . . . . . . . . . . . . 1

1.1 .1 Need/Justification . . . . . . . . . . . . 1

1.1.2 History of Research . . . . . . . . . . . . . . 1

1.2 Objectives . . . . . . . . . . . . . . 3

1.2.1 Basis . . . . . . . . . . . . . . 3

1.2.2 Heirarchy for Magma Energy Research . . . . . . . . 3

1.2.2.1 Magma Resource Analysis . . . . . . . . . . . . 3

1.2.2.2 Magma Fluid Production ............... 3

1.2.2.3 Magma Energy Conversion ... . . . . . . . . . . 4

1.2.3 Work Breakdown Structure . . . . . . . . . . . 5

2.0 FISCAL YEAR ACCOMPLISHMENTS. . . . . . . . . . 5

2.1 Long Valley Operations . . . . . . . . . . . . 5

2.1.1 Drilling and Engineering. . . . . . . . . . 6

2.1.2 Supporting Science ............... 7

2.2 Laboratory and Engineering Support . . . . . . . 9

2.2.1 Drilling Technology ............... 9

2.2.2 Geochemistry and Materials ............. 9

2.2.2.1 Materials Compatibility Activity . . . . . . . . 10

2.2.2.3 Hazards Evaluation Activity . . . . . . . . . 15

2.2.3 Energy Extraction ............... 16

2.2.3.1 Heat Transfer Activity . . . . . . . . . . . 19

2.2.3.2 Surface Plant Activity . . . . . . . . . . . . 46

2.2.3.3 Extraction Experiment Activity . . . . . . . . . 51

3.0 MANAGEMENT ................. 51

3.1 Organization . . . . . . . . . . . . 51

3.2 Inter-Agency Coordination . . . . . . . . . 52

3.3 Meetings ................ 52

3.4 Issues . . . . . . . . . . . . . . . 53

4.0 BUDGET ..................... . . 53

5.0 END-OF-YEAR STATUS ............... 53

6.0 FUTURE PLANS ... . . . . . . . . . . . . 54

6.1 Long Valley Operations . . . . . . . . . . . . . 54

6.2 Laboratory and Engineering Support . . . . . . . 55 


\section{EXECUTIVE SUMMARY}

Major progress during FY88 centered around preparations for beginning a deep exploratory well in Long Valley caldera, CA. The well site is located on the resurgent dome near the peak of over 0.5 meter uplift that has occurred within the caldera since 1980. The well will be drilled to $20,000 \mathrm{ft}$. or $500^{\circ} \mathrm{C}$ in four phases spanning four to five years. During the year, the well site 51-20 on Santa Fe Geothermal lease holding was approved by a 10-member DOE panel headed by Bennie DiBona. Following this, the well design was finalized, a plan of operations was developed and the permit application filed. Numerous meetings were held throughout the year with permitting agencies and local governing bodies to explain objectives and plans for drilling the magma exploratory well. Permit approval was indicated but not finalized by year end.

Significant scientific interest in the magma exploratory we11 was expressed during a two-day workshop held in Albuquerque and attended by about sixty geoscientists and engineers. Results of the workshop will be published as a science guide to add-on measurements directed at understanding the evolution of Long Valley caldera. Several meetings were held with the Interagency Coordinating Group of the Continental Scientific Drilling Program to establish procedures for funding supporting scientific measurements in the well. A management plan to coordinate interagency support was developed by DOE/GTD but not finalized by year end.

Our work in energy extraction combined downhole heat transfer modeling with realistic surface power conversion cycles to predict optimum operating conditions. Energy extraction rates of 30 to 50 MWe per well are predicted. Additionally, first-of-a-kind convective heat transfer measurements were made in a magma simulant fluid having the characteristic of very large viscosity variation. From these measurements, correlations were developed that will improve our magma convection heat transfer calculations for downhole heat exchangers. Geochemistry studies showed that minor amounts of iron in the hydrothermal fluid can effectively prevent quartz dissolution and may, therefore, be used to limit silica scaling in the heat extraction system. We began to measure rates of vapor exsolution during isothermal decompression to evaluate hazards associated with drilling into a magma body under high pressure. 


\subsection{INTRODUCTION}

\subsection{Background}

\subsubsection{Need/Justification}

Thermal energy contained in magmatic systems represents a huge potential resource. In the U.S., useful energy contained in molten and partially-molten magma within the upper $10 \mathrm{~km}$ of the crust has been estimated at 50,000 to 500,000 Quads. The objective of the Magma Energy Extraction Program is to determine engineering feasibility of locating, accessing and utilizing magma as a viable energy resource. Engineering feasibility will depend on size and depth of the resource; problems of completing wells in magma; drilling costs; energy extraction rates; and material life times.

\subsubsection{History of Research}

The current magma program follows a seven-year, DOE/OBES funded Magma Energy Research Project that initiated the concept of energy extraction directly from crustal magma bodies. This study examined the scientific feasibility of locating and drilling into magma and then extracting useful quantities of energy. Theoretical calculations with supporting laboratory and field measurements were used to show that there are no fundamental, theoretical or physical barriers that prevent the direct extraction of energy from magma. As a result of this study, it was concluded that magma energy utilization is scientifically feasible. Two different scientific review panels agreed with this conclusion.

The current DOE magma energy program began during FY84. One of the first significant accomplishments was an evaluation of twenty-one potential magma sites for suitability of carrying out a long-term energy extraction experiment. This evaluation plus additional geophysical measurements at Long Valley caldera and Coso Hot Springs led to the selection of Long Valley caldera as the primary site for magma field experiments.

Early in the program, two system studies were completed. The first, by Well Production Testing, Inc., included a preliminary design of a magma power plant. Major results from this study include: (1) a $6 \mathrm{~km}$ well drilled and completed into magma at Long Valley was estimated to cost $\$ 16 \mathrm{M}$, (2) plant capital costs were estimated to be $\$ 1.34 \mathrm{M}$ per $\mathrm{MW}$ of installed electrical capacity, and (3) energy extraction rates of 20 MWe were predicted for the base case heat exchanger system. The second study was a combined Sandia/WPT evaluation of the economics of magma power generation. Economic calculations determined the price that would need to be charged for electricity in order to balance the costs of power generation and provide a real rate of return of 108 . Using best estimates for input parameters, based on the WPT magma power plant design and modeling of energy extraction, magma-based electricity prices would be in the neighborhood of 80 to $110 \mathrm{mils}$ per kilowatt hour. These prices are higher than current prices of 50 to $70 \mathrm{mils}$ for fossil fuels and 60 to 


$$
11
$$

85 mils for hydrothermal resources, but below current prices for new nuclear plants. Based on the uncertainties associated with well costs and energy extraction rates, the conclusion at this point is that magma appears to be in the same "economic ballpark" with other energy resources. In addition, the analysis identified well cost, well productivity and well lifetime as the parameters most critical to the economics of magma generated power.

In the geochemistry/materials area, significant accomplishments include characterization of rhyolitic magma at Long Valley. In situ mineral compositions and volatile concentrations have been determined by analyzing rhyolite glass at the surface and glass inclusions in rapidly quenched tephra. Following characterization, seventeen commercially available materials were evaluated for compatibility with the Long Valley program. Analysis of reaction productions from materials tests showed that oxidation is the main corrosion problem in rhyolitic magma. Considerations of corrosion resistance, hightemperature strength, and cost resulted in the choice of nickel-base superalloys for use directly in rhyolitic magma. These alloys will survive the direct magma environment for periods of several months, which is sufficient to deal with operational down times. During normal operation, cooling fluids will be circulated through the magma heat exchanger so that cooler, solidifled magma will contact heat exchanger surfaces.

Progress in drilling has centered around identification of major problem areas associated with drilling a deep hole into magma. Preliminary well completion programs were developed by Well Production Testing, Inc. for magma wells in a typical Long Valley location. The computer code GEOTEMP was then used at Sandia to estimate drilling fluid temperature profiles for the deep wells. This led to identification of the need for insulated drill pipe for deep drilling in this environment. With insulated drill pipe, bottom hole temperatures can be maintained near $100^{\circ} \mathrm{C}$, while temperatures will approach $650^{\circ} \mathrm{C}$ without insulation. Problems of borehole creep during both normal drilling and loss of fluid circulation were analyzed. The results were generally encouraging. Displacement of the wellbore wall during drilling was calculated to be only a few millimeters and, therefore, not a problem. Results that address the second problem show that at least one day is available to regain circulation before significant displacement takes place.

Several energy extraction concepts have been evaluated. Analyses and experiments have resulted in a conceptual design for energy extraction in a silicic magma typical of Long Valley. Energy extraction is accomplished by circulating a fluid through a solidified and fractured region that is sealed within the main magma body. The solidified region is grown during energy extraction, and fractures are created by very large thermal stresses in the solidifying material. Numerical simulation of the complete energy extraction process was begun during FY87. Several important features of the process are: (1) fluid pressure in the heat exchanger will be well in excess of the 
critical pressure of water; (2) density imbalance between the injection and return flow paths will allow the well to self-flow as an open thermosyphon; (3) wellhead pressures can be controlled so that neither flashing nor two-phase choking will occur in the well, and (4) net energy extraction rates of 30 to 50 MWe per well are predicted.

\subsection{Objectives}

\subsubsection{Basis}

Program objectives are established to guide the determination of engineering feasibility of the magma energy concept. Objectives address the major technical issues of resource size and depth, drilling and completion, energy extraction, and material lifetime.

\subsubsection{Hierarchy for Magma Energy Research}

The Level 1 objective for magma research is to improve current technology to the point where electricity could be produced experimentally from one or more inferred magma energy resource sites in a cost range of 10 to 20 cents $/ \mathrm{kWh}$ by the year 2000 .

\subsubsection{Magma Resource Analysis}

The Leve1 2 objective for magma resource analysis is to improve the technology for locating and characterizing magma bodies by drilling into molten rock by 1994 .

The Leve1 3 objective is to understand the nature of geophysical anomalies at the Long Valley caldera using actual well observation data, and verify the depth and lateral extent of a magma body by 1992 . Issues: A major magma energy engineering feasibility issue is whether crustal magma bodies can be located with sufficient accuracy to position drill holes. Long Valley caldera is a large silicic volcanic center typical of the resource base upon which the estimate of 50,000 to 500,000 quads was made. An exploratory well deep into the caldera system will provide important new information about the current state of magma at this location as well as provide a test of existing geophysical models that predict magma at depths of 5 to $7 \mathrm{~km}$ beneath Long Valley.

\subsubsection{Magma Fluid Production}

The Level 2 objectives for magma fluid production are to: (1) design the first generation technology needed to extract energy from a magma body by 1992; and (2) dri11, complete, and test a magma energy extraction well capable of producing $30 \mathrm{MWt}$ by 1995 .

The Leve1 3 Objectives are to:

1. Evaluate performance of materials in the corrosive and volatile-rich magma environment for use in drilling tools by 1992 . 
Issues: Engineering materials must be selected that will survive drilling into magma, downhole measurements, and energy extraction. Energy extraction hardware or materials may be exposed to two environments: (1) operating conditions where the magma surrounding the heat exchanger is solidified and at a temperature near $500^{\circ} \mathrm{C}$ and (2) loss-of-fluid conditions where temperatures would reach original in situ conditions of $900^{\circ} \mathrm{C}$.

2. Design and develop technology capable of drilling into molten magma at temperatures of at least $900^{\circ} \mathrm{C}$ and total depths of at least 5 km by 1992 .

Issues: Conceptually, deep crustal magma bodies can be drilled with the same technology used to core Kilauea Iki lava lake during the Magma Research Program. Additional technology that needs to be developed for the deep crustal bodies includes: (1) well casing and high temperature cements to contain the much higher pressure; (2) larger-scale drilling equipment and fluid flow rates; (3) insulated drillpipe to deliver cool fluids to the bit; and (4) high-temperature weighting material.

\subsubsection{Magma Energy Conversion}

The Leve1 2 objectives for magma energy conversion are to: (1) determine design specifications of required energy conversion subsurface and surface equipment by 1996; and (2) determine the engineering feasibility of extracting thermal energy from a magma chamber by 1999 .

The Leve1 3 objectives are to:

1. Evaluate heat transfer effectiveness between a magma body and water circulating in the energy extraction wellbore.

Issues: The energy extraction rate has a controlling influence on the economic viability of magma energy. An open heat exchanger concept, in which fluid is circulated through the interconnecting fractures in the solidified region around the drilling tubing, offers the promise of very high rates of energy production on the order to 30 MWe per well.

2. Predict rates for dissolution of silicate minerals and the composition of fluid in a rock-to-water heat exchanger system, and evaluate the potential for loss of permeability due to precipitation of secondary minerals by 1995 .

Issues: Continued operation of the open heat exchanger may be affected by dissolution of silicate minerals, the composition of fluid in the rock/water heat exchange system, and the precipitation of secondary minerals.

3. Evaluate magma degassing hazards associated with drilling and energy extraction at Long Valley, CA.

Issues: The potential hazards associated with drilling into an active silicic magma body need to be properly addressed before such drilling is proposed to permitting agencies. 


\subsubsection{Work Breakdown Structure}

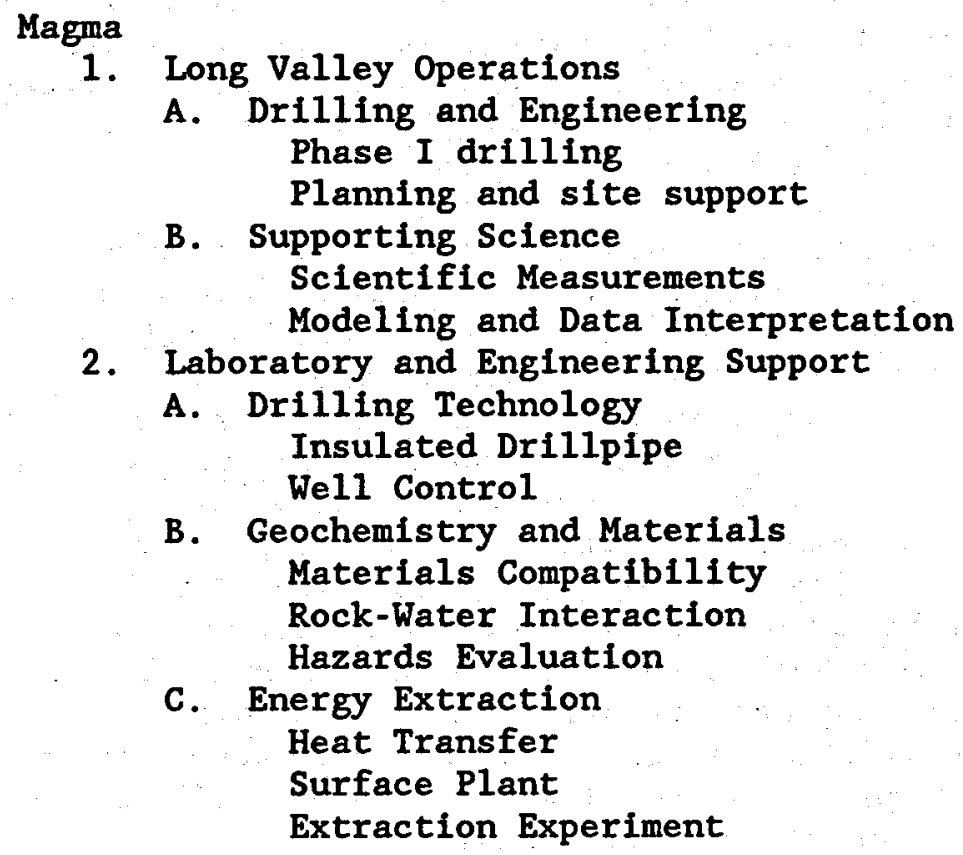

The objectives described above in Section (b) apply directly to the elements of the work breakdown structure.

\subsection{FISCAL YEAR ACCOMPLISHMENTS}

\subsection{Long Valley Operations}

Selection of the drill site for the Long Valley exploratory well was finalized. The site 51-20 on land leased by Santa Fe Geothermal was chosen. This location is on the resurgent dome near the peak of uplift that has occurred within the caldera since 1980. A DOE panel met in Albuquerque during January 1988 to review the site selection process and voted unanimously to approve the resurgent dome site. Several meetings with permitting agencles were held throughout the year, and final approval of the site by the Bureau of Land Management was indicated by year end.

In June 1988, a magma science workshop was held in Albuquerque to plan supporting scientific experiments that could be carried out during exploratory well drilling. The well will be considered as a hole-of-opportunity by the Interagency Coordinating Group that oversees the U.S. Continental Scientific Drilling Program. Supporting scientific experiments will be funded by member agencies in the ICG (NSF, USGS, and DOE/OBES) through the normal proposal submittal process. The output from the magma science workshop is a "Science Guide" outlining experiments of interest in the four following areas: (1) Geology, (2) Geophysics, (3) Hydrothermal Systems, and (4) stress and Mechanics. The guide was prepared in draft form during FY88 and will be published early in FY89. 


\subsubsection{Drilling and Engineering (J. T. Finger)}

\section{Description}

The magma energy exploratory well will be drilled in four yearly phases near Mammoth Lakes, California. Its aim is to drill toward, but not into, the magma body that is believed to underlie Long Valley caldera. The target is a depth of $20,000 \mathrm{ft}$ or a bottomhole temperature of $500^{\circ} \mathrm{C}$, whichever comes first.

Primary benefits of the well will be refinement of the geophysical description of Long Valley caldera, verification of our ability to locate magma bodies, and development of drilling technology for very high temperatures. All of these points have direct bearing on plans for a large-scale energy extraction experiment, which will require a hole that is deeper, larger, hotter, and more expensive than the exploratory well. The larger well's cost can be minimized, however, by the information gained and technology developed in the precursor. The lithology of the site, the exact depth to the magma body, the possible presence of abnormally-pressured zones, the chemistry of any produced fluids, and the formation stability will all be crucial in planning another well. Also the opportunity to test high-temperature drilling fluids, tools, and instrumentation in a realistic environment will aid the development of the technology necessary to drill successfully into magma.

\section{FY 88 Progress}

Most of this year's effort has been directed to the acquisition of the permits and approvals necessary for commencement of drilling. The drilling permit required the submission of a detailed Plan of Operation including well design, casing program, rig layout, site evaluation, and schedule. Once the BLM received the plan, they reviewed it, called for public comment, and rendered a decision on the Plan. Sandia participated in all these stages, including a pubic briefing for the residents of Mammoth Lakes. Once the BLM decision to approve the permit was issued, there was still a waiting period for public protest before we actually could get the drilling permit. That period passed without incident, and we had the drilling permit in hand approximately mid-October. Since it was too near snow season by then to begin work, our start date is now June 15, 1989. We have also been notified by the California Regional Water Quality Control Board that we must submit application for waste discharge (drilling fluids and cuttings) for the last three phases of drilling. Since this does not affect the FY89 work, it is not an immediate necessity, but we have submitted all the required information to the Board. They have assured us that it is fairly straightforward and should be approved within a couple of months.

The other major activity of this FY has been organizing the contracting and management structure for this project. The largest part of the work will be performed by the drilling contractor, either by his own employees or by third-party suppliers. Other contracts, such as casing and logging, will be placed directly by Sandia. During drilling operations, our intention is to have a Sandia representative and a contract drilling engineer on site at all times. A very detailed drilling contract has been written and will be submitted for quotations. 
Milestones - "Deliver letter of intent concerning the Long Valley drilling to the BLM and the Forest Service." - Complete.

"Select drilling engineer and drilling contractor for Long Valley we11." - Drilling engineer selected; RFQ's to contractors, expect selection by $3 / 89$.

"Spud the Long Valley exploratory we11." - New Date 7/89.

\subsubsection{Supporting Science (John Rundle)}

\section{Description}

A major objective of the Magma Energy Extraction has been to find a suitable site for drilling into, and extracting energy from, a continental magma body. During FY88, this requirement was finally met with the selection of the Long Valley caldera as the prime location for the initial phase of drilling.

Long Valley was tentatively selected as the primary location by the project during FY87, on the basis of the available geophysical and geological evidence. The geophysical evidence is both structural and dynamic in nature. The structural evidence originates principally from the great number of seismic studies, both active and passive, that have been conducted throughout the region in the years since 1970. Most of these studies have indicated the existence of highly anomalous regions directly beneath the caldera, which a variety of considerations dictate to be magma. The dynamic evidence is the exceptionally large, time-dependent deformations which the caldera has undergone since 1980 , as well as the intense local seismicity both within the caldera and regionally. In fact, recent measurement of Iine length changes made within the last month confirm that the caldera is still deforming at rates approximately an order of magnitude more rapidly than that common for the San Andreas fault in southern California. The Long Valley rates, which are on the order of a part per million per year, correspond to perhaps 2 to 3 centimeters of extension per year across the caldera. As the deformation is quite local within the caldera, the only logical explanation for it is the continued injection of magma at depth.

\section{FY88 Progress}

Following the selection of Long Valley by Sandia project personnel, a panel of knowledgeable scientists and engineers was appointed by DOE/GTD to review and approve the decision at a meeting in Albuquerque, NM, during January 14-15, 1988. This panel consisted of:

Bennie DiBona

Joel Renner

Paul Kasameyer

Dick Dondanville

Gary Crosby

David Hill

Chris Higgins

Mike Wright

Chandler Swanberg

Bill Berge
Terra Tek

INEL

LLNL

UNOCAL

Phillips

US Geological Survey

CDMG

UURI

GEO

Berge Resources
Chairman

Vice Chairman 
Several presentations were given to the panel providing the rationale for selection of the resurgent dome site. Evidence supporting an alternative site in the west moat of the caldera was also presented by geoscientists from LBL and the U.S. Geological Survey. After due deliberation, the panel unanimously voted in favor of the site on the central resurgent dome. Preparations thus began for drilling at the site, which is coincident with a large drill pad prepared by Santa Fe Geothermal Corporation, and which is available for project use.

The selection of the Long Valley site has now provided a sharp focus for planning for the engineering and scientific needs of the project. Following the magma energy review panel meeting in January, J. C. Dunn, J. B. Rundle, and J. Hermance traveled to Sacramento, California, on February 16, 1988, and to Mammoth Lakes, California, on February 17, 1988, to initiate discussions with state and local authorities regarding joint cooperative efforts on the project. Meetings were held with the acting California state geologist, Brian Tucker and his staff, and with Ray Windsor, city manager of Mammoth Lakes, Andrea Lawrence of the Mono County Board of Supervisors, and with Dan Lyster, director of the Mono County Energy Management Department. Close cooperation with these persons, who represent the appropriate state and local agencies, will be of continuing importance to the project.

Formal planning for the scientific aspects of the drilling project began at a workshop held in Albuquerque during June 8 and 9,1988 . Approximately 60 persons attended, of whom more than two-thirds were from universities, government agencies, and national laboratories other than Sandia. The purpose of the workshop was to inform the external community about the opportunities presented by the Long Valley drilling, and to solicit input for a guide to scientific opportunities in the well. The morning of the first day was devoted to reviewing the engineering and programmatic goals for the deep exploratory well. Discussion was also given of the geologic setting, and of geophysical results obtained by a decade of previous work. Representatives from the U.S. Geological Survey, DOE/Office of Basic Energy Sciences, and the National Science Foundation also summarized their agencles interest in the project.

Following the introductory presentations, the meeting broke up into four groups: (1) Hydrothermal Systems; (2) Geology/Petrology; (3) Geophysics; and (4) Stress and Mechanics. These groups met during the afternoon of the first day and the morning of the second day. Chairmen of the group were, respectively; David Blackwell, Southern Methodist University; Roy Bailey, U.S. Geological Survey; Jack Hermance, Brown University; and Herbert Wang, University of Wisconsin. The focus of the individual groups' discussions was on providing a written summary of significant experiments which might conceivably be done in the well, for inclusion in the science guide. This goal was successfully accomplished. On the afternoon of the second day, the results of the various individual discussions were summarized by the group chairmen. 
During the period since the June workshop, revision of the science guide has been the major focus of efforts. This document, which is now in draft form, is expected to be finished shortly, and should be available for general release by June 1989. It is hoped that it will provide useful suggestions for persons interested in designing experiments for the exploratory well program.

\subsection{Laboratory and Engineering Support}

Significant progress in developing and understanding magma energy extraction processes was made in five areas: (1) fundamenta1 mechanisms of solidifying and thermally fracturing magma; (2) convective heat transfer within the fractured, solidified material; (3) convective flow in the molten magma body and heat transfer from the magma to the cooled heat exchanger; (4) numerical simulation of the overall energy extraction process; and (5) thermodynamics of energy conversion in a magma power plant at the surface. Results in these areas increase our predictive capabilities for estimating downhole heat exchanger performance and magma power production. This leads to the estimate of about $30 \mathrm{MWe}$ for a single magma well.

Our past materials work has shown that nickel-base superalloys can survive the full in situ magmatic conditions for periods of at least one month. Heat exchanger operating conditions will be less severe in temperature, but hydrothermal fluids will be present. Material tests at $500^{\circ} \mathrm{C}, 50 \mathrm{MPa}$, and with hydrothermal fluids show almost no oxidation after 10 days. Longer-term tests will be run in the future. silicate mineral dissolution in a downhole fractured magma heat exchanger is being studied to avoid problems of scaling or permeability reduction. Results this year showed that minor amounts of iron in the hydrothermal fluid can effectively prevent quartz dissolution by precipitation of magnetite on the exposed quartz surface: This mechanism may be used to limit silica scaling in the heat extraction system. Also during the year rates of magmatic vapor exsolution were measured during isothermal decompression. These rates will be used in fluid flow and well control models to evaluate hazards associated with drilling into a magma body at pressures up to lithostatic.

\subsubsection{Drilling Technology}

Drilling technology development for the magma project is funded through Hard Rock Penetration Research. Activities to date have focused on development of insulated drill pipe for drilling in deep, hot environments. The following material in this section is reported in the Hard Rock Penetration Annual Report and duplicated here.

\section{Description}

Most high-temperature arilling problems worsen as the rock gets hotter. Since, by definition, our objective in geothermal programs is to drill hot rock, these problems are generic and are typically solved by using new and/or better (and usually more expensive) materials. One of the few opportunities to circumvent this approach is to keep the drilling fluid, wellbore, and drill string relatively cool by using insulated drillpipe (IDP). In conventional hot rock drilling, 
the steel drillpipe is a good conductor and acts as a counterflow heat exchanger. That is, the temperatures of the drilling fluid inside and outside the drillpipe tend to converge and are almost the same at any given depth. Although the fluid becomes very hot at the bottom of the we11, it returns to the surface only slightly above its original temperature, and it has not removed much heat from the wellbore system.

With IDP, the fluid arrives at the bottom of the well much cooler than in the conventional case, which is good for the bit, the tubulars, and the drilling fluid. The cooler fluid is also much more effective at transferring heat from the formation, so the fluid returns significantly hotter than the inlet conditions, and the formation is cooler than in the conventional case.

Principal activity in this project has been development of an IDP design that will be thermally effective at a reasonable cost. Several companies in the U.S. have made insulated tubulars, primarily tubing for Enhanced $0 i 1$ Recovery steam injection, but they have no experience with drillpipe. All U.S. insulated tubing manufacturers were contacted for a show of interest in the IDP project, and contracts for preliminary designs were placed with the two companies that responded. Their trial designs have been iterated with Sandia refinements, and are now ready for RFQ's on prototype production.

FY88 Progress - Much of this year's effort has been devoted to two problems: (1) reducing the pipe cost--some tool joint designs could require extensive and expensive fixturing to manufacture, and (2) reducing the heat transfer through the IDP joints -- for each 40 foot length of IDP, the heat transfer at an uninsulated joint is at least five times that of the entire insulated section. Redesign of the tool joints has lowered the manufacturing cost for small quantities and has reduced the joint heat transfer to a value about equal to the insulated section. Calculations to assess the effect of different joint insulation levels are complete. The material to be used as the joint insulation is not yet defined.

Once the prototype IDP is on hand, we must verify certain minimum performance levels. Test plans for thermal and mechanical lab tests are under discussion with Sandia's Development Testing Directorate, and the Magma Energy Exploratory Well drilling contract is written to include use of the prototype IDP in that project if the pipe is available in time.

FY88 Milestones - "Complete definition of test plan and procurement of prototype drillpipe." Because of design changes, the procurement has not been done; RFQ's are expected by $1 / 89$. New date: $6 / 89$.

"Complete preliminary tests of thermal performance." This is delayed in step with the previous milestone. New date: 11/89.

\subsubsection{Geochemistry and Materials (H. Westrich and W. Casey)}

Description

This section involves the use of in-house high-temperature, high- 
pressure laboratory equipment to experimentally evaluate three geochemical objectives related to the Magma Energy Project; they include materials compatibility, silicate mineral dissolution, and volcanic hazards. The following is a list of publications in FY88 under this task:

Westrich, H. R., Stockman, H. W. and Eichelberger, J. C., 1988, Degassing of rhyolite magma during ascent and emplacement. Jour. Geophys. Res., 93, B6, 6503-6511, 1988.

Casey, W. H., Westrich, H. R., and Arnold, G. W., 1988, Surface chemistry of labradorite feldspar reacted with aqueous solutions at $\mathrm{pH}=2,3$, and 12 . Geochim. Cosmochim. Acta, in press.

\subsubsection{Materials Compatibility Activity}

\section{FY88 Progress}

The durability of heat exchanger materials in a magmatic and hydrothermal environment is crucial to the long-term feasibility of heat extraction in the Magma Energy Project. Magma-metal compatibility tests were made at $850^{\circ} \mathrm{C}$ and $150 \mathrm{MPa}$ in a hydrous rhyolite using commercially available nickel-base alloy pipe and were found to react similarly to other generic nickel-base alloys. The oxidation is the principal corrosion problem of these alloys and is usually limited to less than $20 \mu \mathrm{m}$ in thickness. These compatibility tests have demonstrated the durability of nickel-base superalloys for durations up to a month under magmatic conditions. Fluid-metal compatibility tests are currently being evaluated involving reaction of both iron- and nickel-base superalloys (Table 1) with hydrothermal fluids at normal operating conditions $\left(500^{\circ} \mathrm{C}\right.$ and $50 \mathrm{MPa}$ ) for the heat exchanger. Initially, the nickel-base alloys were severely oxidized, while iron-base alloys were not. Subsequent tests have shown that this was the result of a galvanic couple between the test samples and the iron-base support rod in the cold seal pressure vessel. Replacing the metal support rod with an alumina or an alumina/silica rod eliminated this problem. Results for reactions up to 4 days in duration with aqueous solutions ranging in composition from deionized water to an aqueous brine containing $1000 \mathrm{ppm}$ chloride, 500 ppm fluoride and $100 \mathrm{ppm}$ sulfate indicate that there was little oxidation of the test alloys. Most were tarnished, but only 316 SS and A286 exhibited a measurable oxide rind $(-10 \mu \mathrm{m})$ after reaction in deionized water for 10 days (Figure 1 ). In some tests, rhyolite glass was added in order to buffer the aqueous fluid with soluble rock components. Aluminosilicate minerals (feldspars) were found on the wire samples, while silica had precipitated at the cool $\left(-200^{\circ} \mathrm{C}\right)$ end of the pressure vessel (Figure 2). The precipitation of silicate minerals onto metal surfaces are actually desirable since it would further protect the heat exchanger from reaction with aqueous fluids. 


\section{Metal-Fluid Compatibility Test Materials}

\begin{tabular}{|c|c|c|c|c|c|c|c|c|}
\hline & \multirow[t]{2}{*}{ ALLOY } & \multicolumn{7}{|c|}{ COMPOSITION (wt.z) } \\
\hline & & Fe & $\mathrm{Cr}$ & $M n$ & $\mathrm{Ni}$ & Co & Mo & Others \\
\hline & Stainiess Steol & & & & & & & \\
\hline \multirow[t]{6}{*}{$\begin{array}{l}\stackrel{-1}{0} \\
\stackrel{\sigma}{\sigma} \\
0 \\
H\end{array}$} & $\begin{array}{l}316 \text { (Austenitic) } \\
\text { Superalloys }\end{array}$ & 68.7 & 17.4 & 1.6 & 9.5 & 0.0 & 1.8 & $0.6 \mathrm{Si}, 0.3 \mathrm{Cu}$ \\
\hline & A286 (Fe-base) & 58.1 & 15.3 & 0.2 & 24.7 & 0.0 & 0.8 & $0.5 \mathrm{SI}, 0.4 \mathrm{Al}$ \\
\hline & $320 L R$ (Fe-bose) & 37.9 & 20.0 & 1.9 & 33.8 & 0.0 & 1.8 & $3.9 \mathrm{Cu}, 0.4 \mathrm{Al}, 0.3 \mathrm{si}$ \\
\hline & $\mathrm{C276} \quad(\mathrm{Ni}-\mathrm{bose})$ & 5.8 & 16.1 & 1.1 & 59.6 & 0.6 & 12.8 & 4.2 W. 0.3 Al. $0.1 \mathrm{~V}$ \\
\hline & C22 (Ni-bose) & 4.5 & 21.9 & 0.7 & 56.3 & 1.8 & 11.0 & $3.5 \mathrm{w}, 0.2 \mathrm{Al}, 0.1 \mathrm{~V}$ \\
\hline & IN625 (Ni-bose) & 1.2 & 22.5 & 0.0 & 65.1 & 0.0 & 8,1 & $2.5 \mathrm{Nb}, 0.2$ SI, $0.2 \pi$ \\
\hline
\end{tabular}




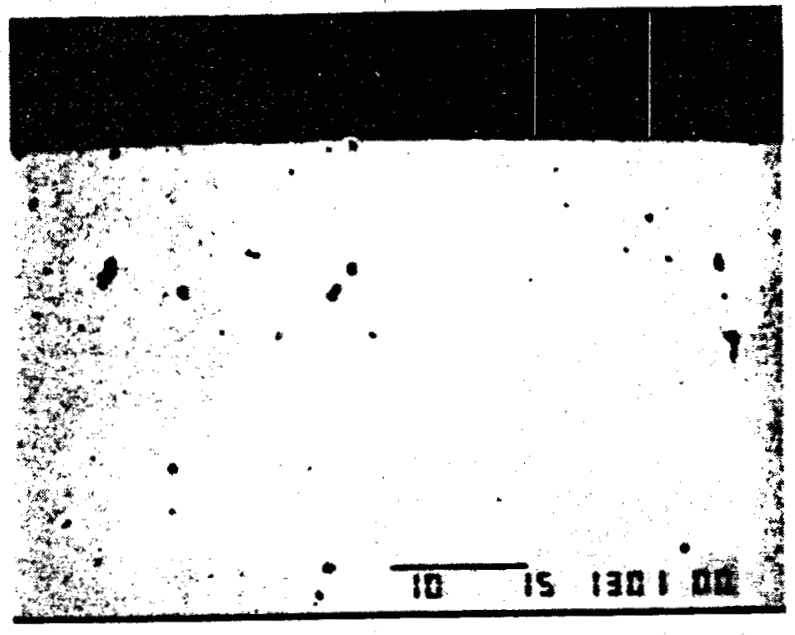

IN625

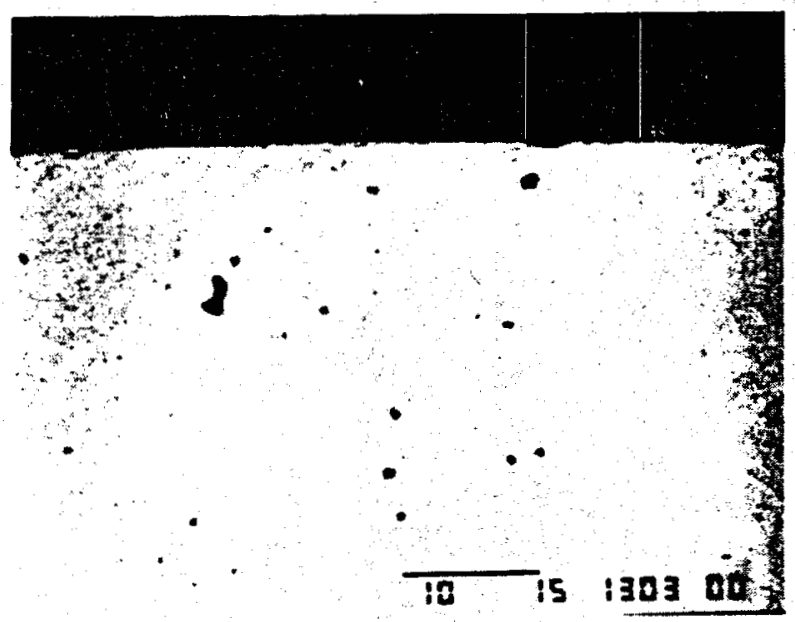

C22

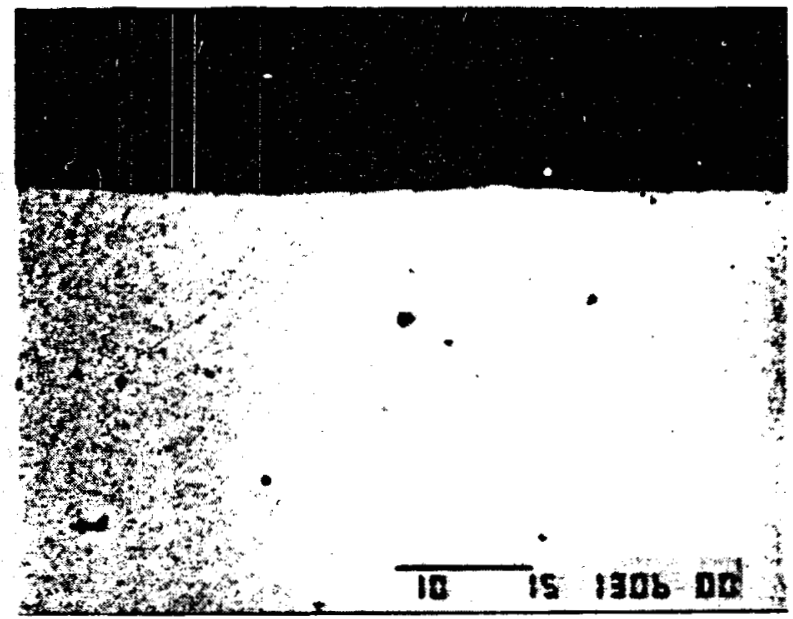

$320 \mathrm{LA}$

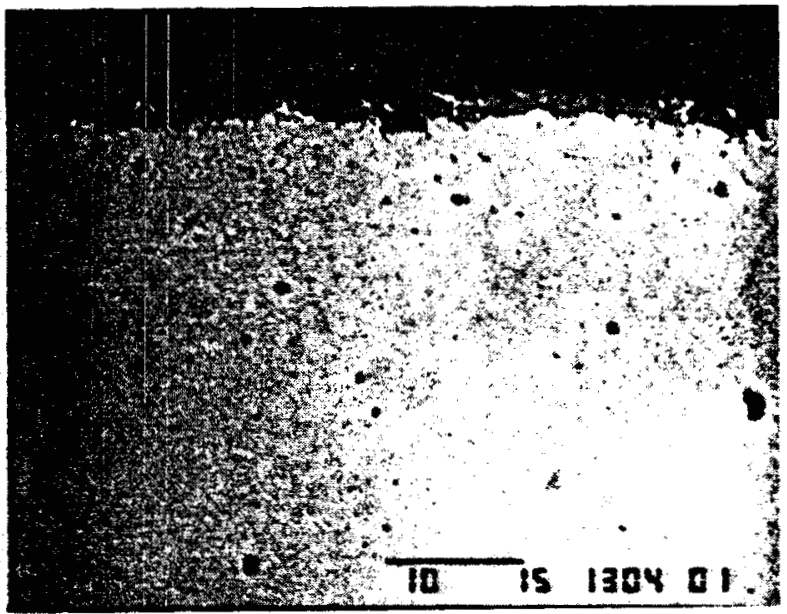

A286

Figure 1. Metal-Fluid $\left(\mathrm{H}_{2} \mathrm{O}\right)$ Compatibility at $500^{\circ} \mathrm{C}, 500$ bars, 10 days. 
Metal-Fluid Compatibiitty Test Surface Coatings at 500 bars

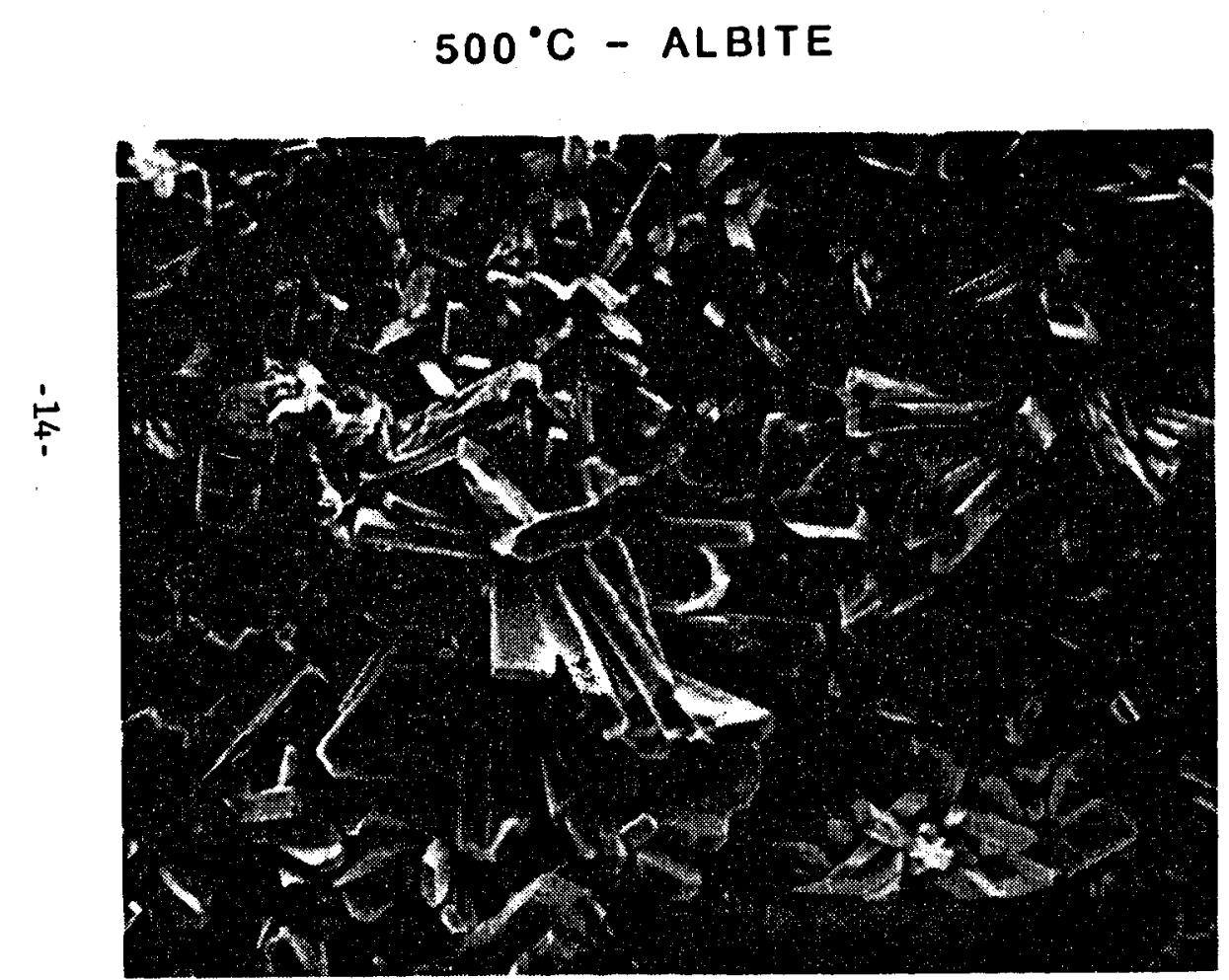

Leaching \& Local Recrystallization $200^{\circ} \mathrm{C}$ - Amorphous Silica

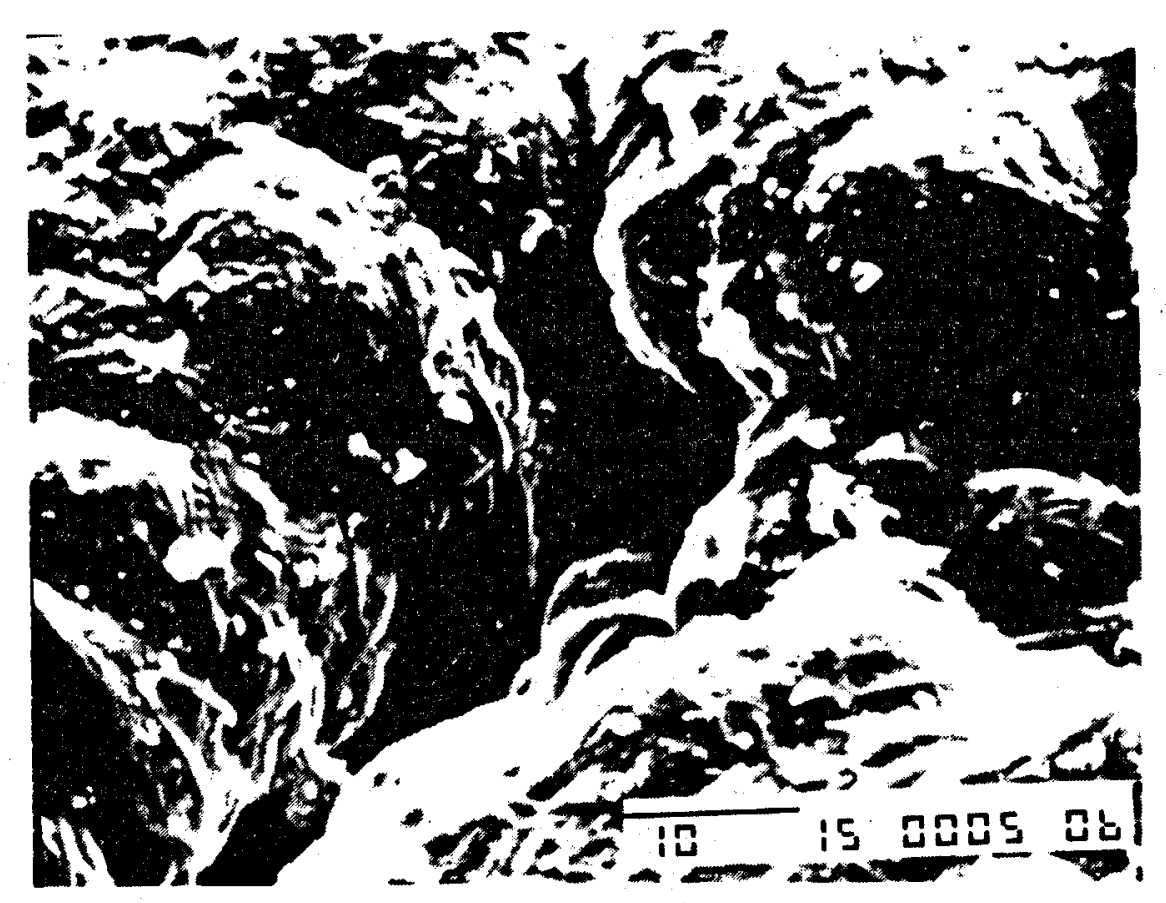

Mass Transport \& Precipitation 


\section{VESICULATION PROCESSES}

\section{ISOTHERMAL DECOMPRESSION}

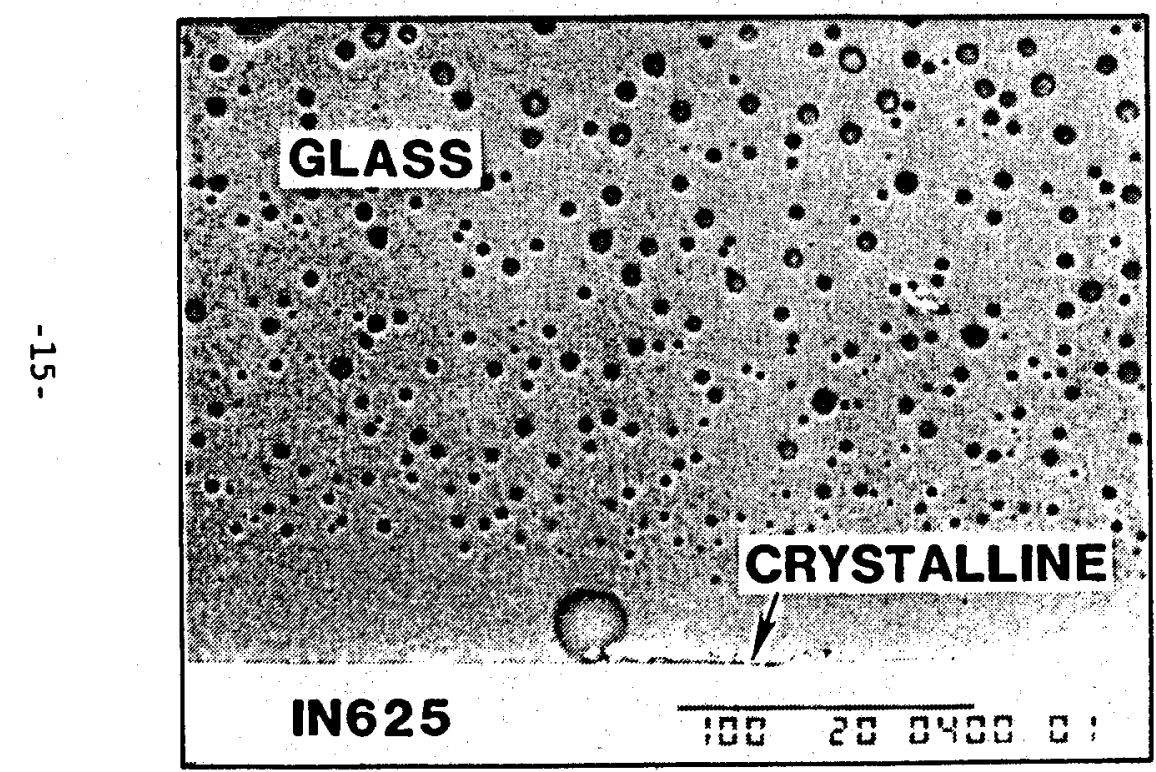

$500^{\circ} \mathrm{C}, 500$ bars, 4 days

\section{ISOBARIC CRYSTALLIZATION}

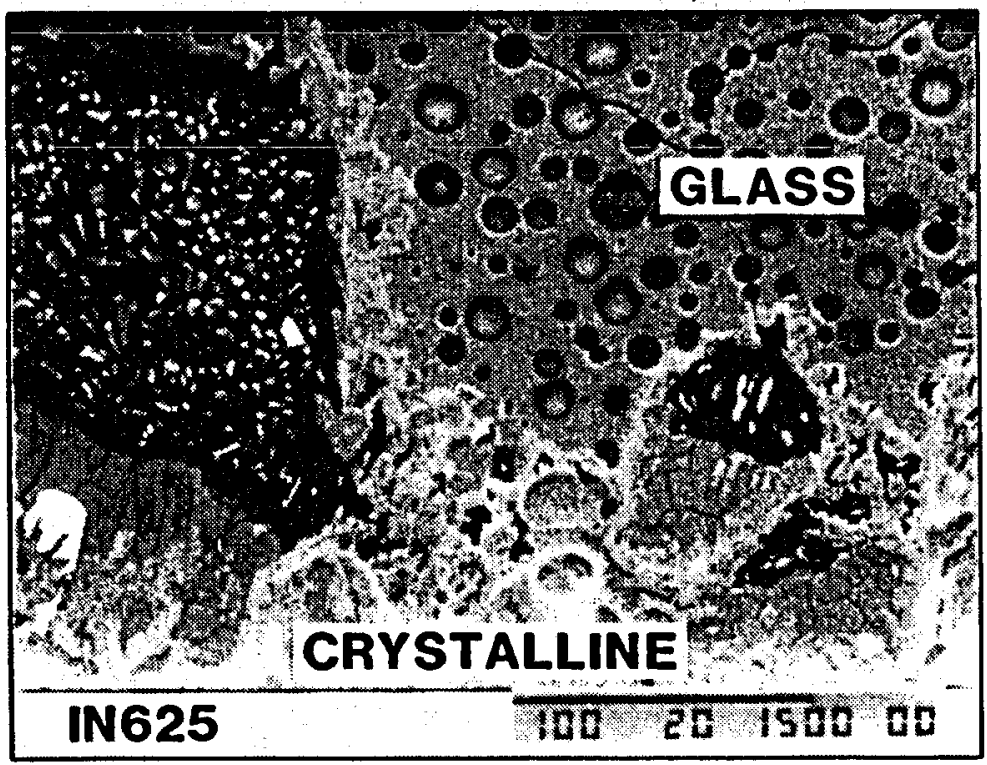

$500^{\circ} \mathrm{C}, 500$ bars, 15 days 


\subsubsection{Rock-Water Interaction Activity}

\section{FY88 Progress}

Downhole Heat extraction in the Magma Energy Project involves direct contact between an aqueous solution and silicate minerals commonly found in crystalline rhyolite magma. Characterizing the dissolution mechanism and the rates of dissolution of these minerals at the temperatures and pressures of the heat-exchanger is important for understanding the hydrothermal processes operating in a geothermal system and avoiding engineering problems, such as permeability changes and scaling. One approach that we are pursuing is to characterize dissolving aluminosilicates at low temperatures and pressures $\left(25-50^{\circ} \mathrm{C}\right.$ and $0.1 \mathrm{MPa}$ ) in order to clarify the mechanics of aqueous dissolution. For this study, we have examined the dissolution of plagioclase feldspar by ion beam characterization of the reacted feldspar and chemical analyses of the aqueous solution. The dissolution mechanism is incongruent in acids, where the rate-controlling step is hydrolysis of the siloxane bonds; dissolution in basic solutions is congruent. Results indicate that dissolution rates are strongly affected by solution $\mathrm{pH}$, temperature, and reaction time, whereas the effects of crystallographic orientation and defect density are minor. The dissolution model predicts that multivalent absorbates, like ferric iron, will decrease the dissolution rate in acids. This line of research is continuing and will be extrapolated to higher pressures and temperatures so that we might better understand and predict feldspar dissolution near the heat exchanger.

The dissolution rates of quartz and muscovite in hydrothermal fluids are also being determined using a Hastaloy $\mathrm{C}-276$ rotating disc autoclave system. Preliminary results from quartz dissolution tests at $200-400^{\circ} \mathrm{C}$ and $40 \mathrm{MPa}$ using a $0.001 \mathrm{M} \mathrm{HCl}$ fluid demonstrated that silica concentrations decreased to below analytical detection limits (10 ppb) after a few days at temperature and pressure. It appears that minor amounts of iron in the hydrothermal system can effectively prevent quartz dissolution by precipitation of magnetite on the exposed quartz surface. This result was not unanticipated from our low-temperature dissolution tests and could be quite useful during heat extraction in a natural system because it might limit silica scaling at or near the heat exchanger. Further measurements of quartz dissolution under a wide range of $\mathrm{P}-\mathrm{T}-\mathrm{X}$ conditions are continuing, especially since dissolution rates are known to vary with temperature, solution $\mathrm{pH}$ and perhaps crystallographic orientation.

\subsubsection{Hazards Evaluation Activity}

\section{FY88 Progress}

Extraction of energy from a downhole heat exchanger in the Magma Energy Project would result in the cooling of the magma body, saturation of the magma with respect to volatiles (especially water), and exsolution of an aqueous fluid. Alternatively, exsolved fluids 
near the heat exchanger, at lithostatic pressures, could pose engineering difficulties and potential safety hazards during drilling, depending upon the rate of vapor exsolution or the hydrostatic pressure of the heat exchanger fluid. Kinetic studies of vesiculation (vapor exsolution) in magma as a result of isothermal decompression during drilling or isobaric crystallization during heat extraction (Figure 3) can help define the magnitude of this potential problem. Vapor exsolution was measured in hydrous ( 3 and 5 wt. $\mathrm{H}_{2} \mathrm{O}$ ) rhyolite magmas after a pressure drop from $150 \mathrm{MPa}$ to $50 \mathrm{MPa}$ in 1-600 minutes at $850^{\circ}$. The equilibrium solubility limit for water in rhyolite at $50 \mathrm{MPa}$ is about $2.75 \mathrm{wt} .8$. The magma that was initially water undersaturated at $150 \mathrm{MPa}$ ( 3 wt. 8 ) reached the solubility level after decompression. However, the magma which was oversaturated at $150 \mathrm{MPa}$ (5.0 wt. \&) did not undergo complete degassing to the low-pressure saturation level. Based upon bulk water analyses, water contents as high as 4.1 wt.8 remained after decompression. These tests should be repeated with ion microprobe analyses of the glassy samples, which will determine whether a water concentration gradient exists. Vesiculation was also experimentally induced in hydrous rhyolite glasses ( 1 to 5 wt. $8 \mathrm{H}_{2} \mathrm{O}$ ) by isobaric crystallization at cooling rates from $150-1^{\circ} \mathrm{C} /$ hour. Examination of the samples show that upon cooling from $150-50^{\circ} \mathrm{C} /$ hour, bubble growth increases with cooling rate or with total water content. At cooling rates $\leq 25^{\circ} \mathrm{C} /$ hour, anhydrous phases (quartz and feldspar) nucleate and grow, saturating the melt with water, eventually forming large vapor pockets upon continued exsolution of water from the melt. These tests will be repeated and will be complemented by water analyses or residual glasses in order to evaluate the kinetics of the vapor exsolution process during heat extraction.

\subsubsection{Energy Extraction (T. Y. Chu)}

\section{Description}

The long-range goal of the Magma Energy Program is to demonstrate the engineering feasibility of magma energy extraction by carrying out a MW-range field demonstration experiment. The energy extraction concept is shown schematically in Figure 4. By appropriate cooling during drilling, we expect to establish a borehole protruding into a body of molten magma; the borehole is surrounded by solidified magma. The volume of solidified magma is expected to be highly fractured due to thermal stress. Energy extraction is accomplished by circulating water from the bottom of the borehole through the fractured volume of solidified magma. Under steady-state operation the extracted energy is balanced by the convective transport of energy from the molten magma to the solidified volume. The energy thus extracted is then converted into useful work at a surface plant.

The first step in achieving the long-range goal is to understand the heat transfer and related processes that are important in the energy extraction scheme; a model that accounts for the interaction of the individual processes downhole can then be established to quantify 
the potential energy extraction rates. Thermodynamic and engineering considerations determine the design of the surface plant for utilizing the extracted energy. Ultimately, in concert with the drilling project, a field demonstration of energy extraction will be carried out.

The following is a listing of publications and presentations in FY88 under this task:

Boehm, R. F., D. L. Berg and A. Ortega, "Modelling of a Magma Energy Geothermal Power Plant," ASME Winter Annual Meeting, Boston, MA, December 1987.

Chu, T. Y., J. C. Dunn, R. P. Wemple, C. E. Hickox, and R. F. Boehm, "Recent Advances in Magma Energy Extraction," Proceedings Geothermal. Program Review VI, San Francisco, CA, April 1988.

Chu, T.Y., "Developing Thermal Convection in an Enclosure with Localized Heating," Open Forum Presentation at ASME National Heat Transfer Conference, Houston, TX, August 1988.

Clarkson, R., N. K. Wendakema, "Study of Mixed Convection Between Vertical Concentric Cylinders," ASME National Heat Transfer Conference, Houston, TX, August 1988.

Hickox, C. E. and T. Y. Chu, "Thermal Convection with Large Viscosity Variation in an Enclosure with Localized Heating," Presentation at the 8th Biennial CUBE Symposium, Albuquerque, NM, November 1988.

Chu, T. Y. and C. E. Hickox, "Thermal Convection with Large Viscosity Variation in an Enclosure with Localized Heating," ASME Winter Annual Meeting, December 1988 (Paper Accepted July 1988). 


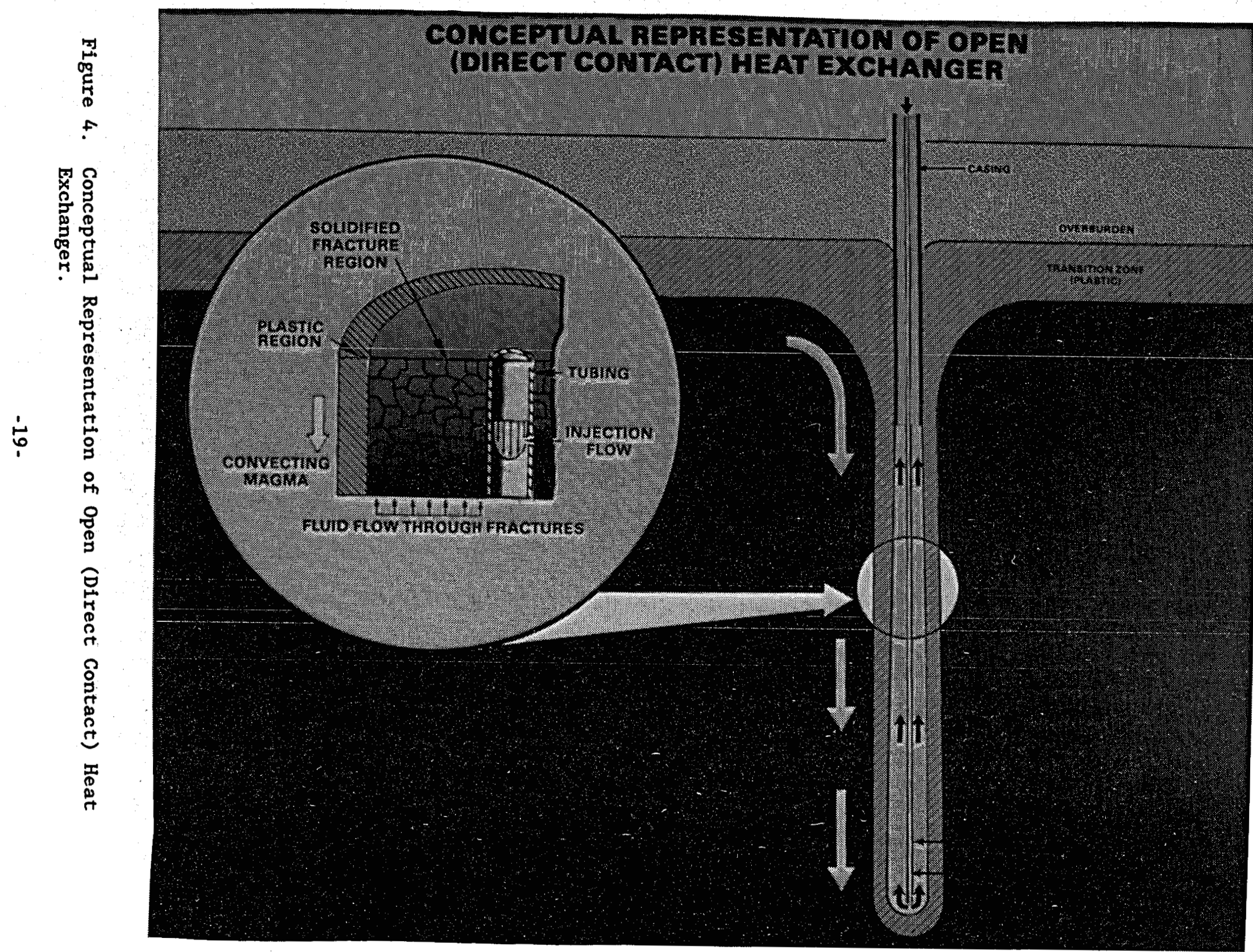




\subsubsection{Heat Transfer Activity}

To evaluate heat transfer processes, our research is addressing four areas: (1) solidification and thermal stress fracturing; (2) fluid circulation and heat transfer in the internally fractured solidified magma; (3) convective transport in molten magma; (4) and numerical simulation of the overall energy extraction process. The first three areas provide the basic understanding of the proposed energy extraction scheme. The last area integrates the individual processes into a numerical model for quantitative evaluation of the energy extraction rates.

\section{FY88 Progress:}

\section{Solidification and Thermal Stress Fracturing}

During the year; a series of dynamic solidification/thermal stress fracturing experiments were carried out to highlight the basic mechanisms of thermal stress fracturing. A terpene phenolic resin was used as a magma simulant. It is transparent with a light amber color. It has a softening point at approximately $125^{\circ} \mathrm{C}$. Its viscosity is highly dependent on temperature in the vicinity of the softening point; and it exhibits qualitatively similar fracturing behaviors as glass when cooled from an elevated temperature. The low melting point of the simulant allows the use of glass test vessels and direct observation of the fracturing process.

Shown in Figure 5 is the final result of a solidification experiment around a $13-\mathrm{mm}$-diameter water cooled probe, operating at $20^{\circ} \mathrm{C}$ in a liter of the molten simulant at $160^{\circ} \mathrm{C}$. The dotted line indicates the approximate extent of solidification. What appears to be small horizontal protrusions are fractures in the solidified crust; note that the fractures do not extend into the outer plastic region of the crust. The fractures form a more or less regular cellular fracture pattern when viewed normal to the direction of solidification (radial). Experiments with flat plate heat exchanger showed similar results. The three dimensional nature of the fracture pattern is shown more distinctly in the close-up view in Figure 6.

Fractures develop as soon as a solidified crust is formed on a surface and continue to grow as the solidified layer grows thicker. The fracture growth occurs by bursts over large patches on a surface, suggesting that the strain energy is only released when a certain threshold is exceeded. A fracture face, exposed when a fracture is cleaved open, with several generations of growth is shown in Figure 7 . The direction of growth deviates slightly with each burst of growth giving the fracture surface an undulating appearance. The amount of fracture extension, marked by arrows in Figure 7, appears to be fairly constant with each burst of growth. During growth, several (typically 5 or 6) fracture cells would form a cluster, but only the fractures forming the outline of the outer boundary of the cluster would grow, resulting in a new cell with increased dimensions. Shown in Figure 8 


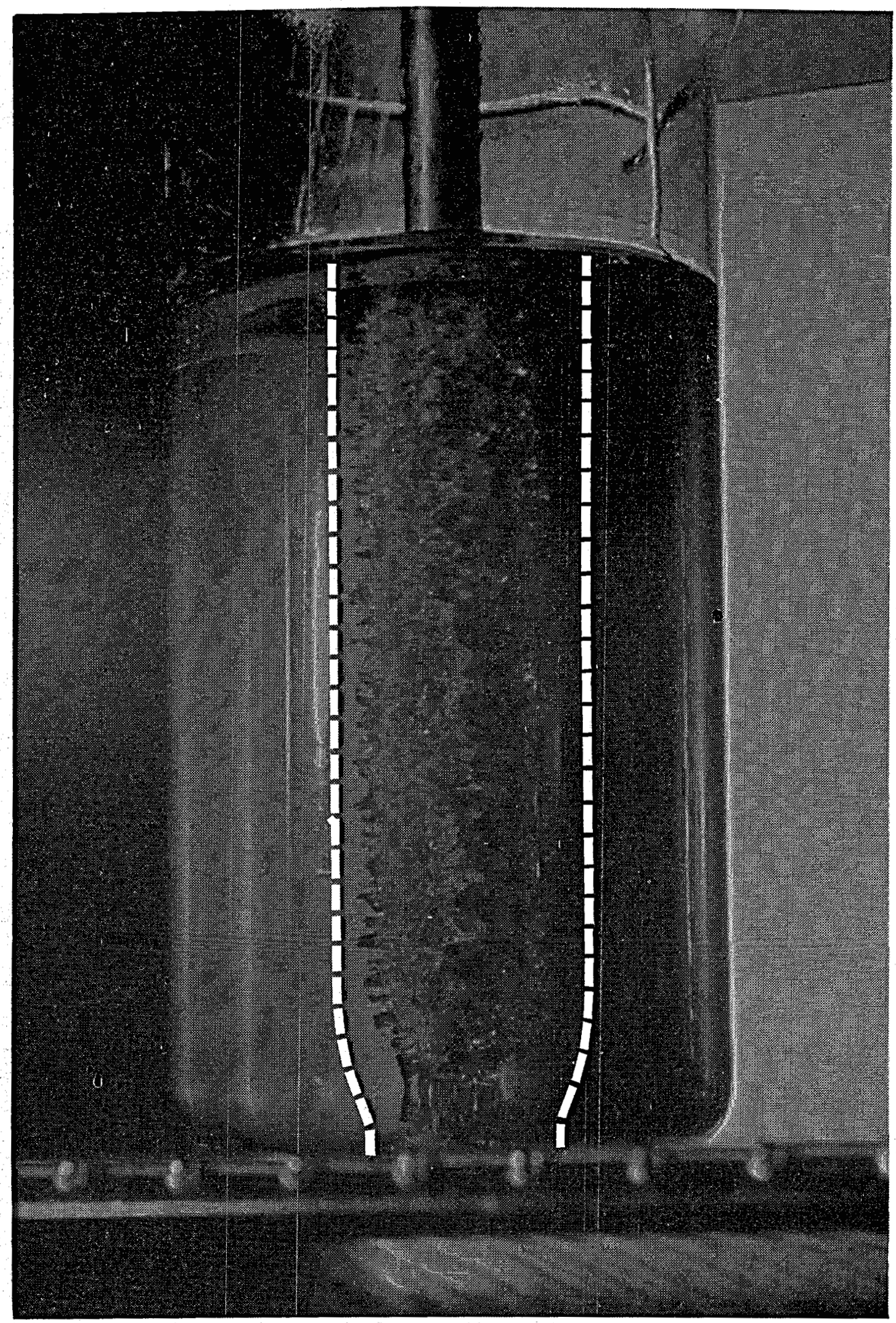

Figure 5. Solidification and fracturing around a cylindrical heat exchanger. 


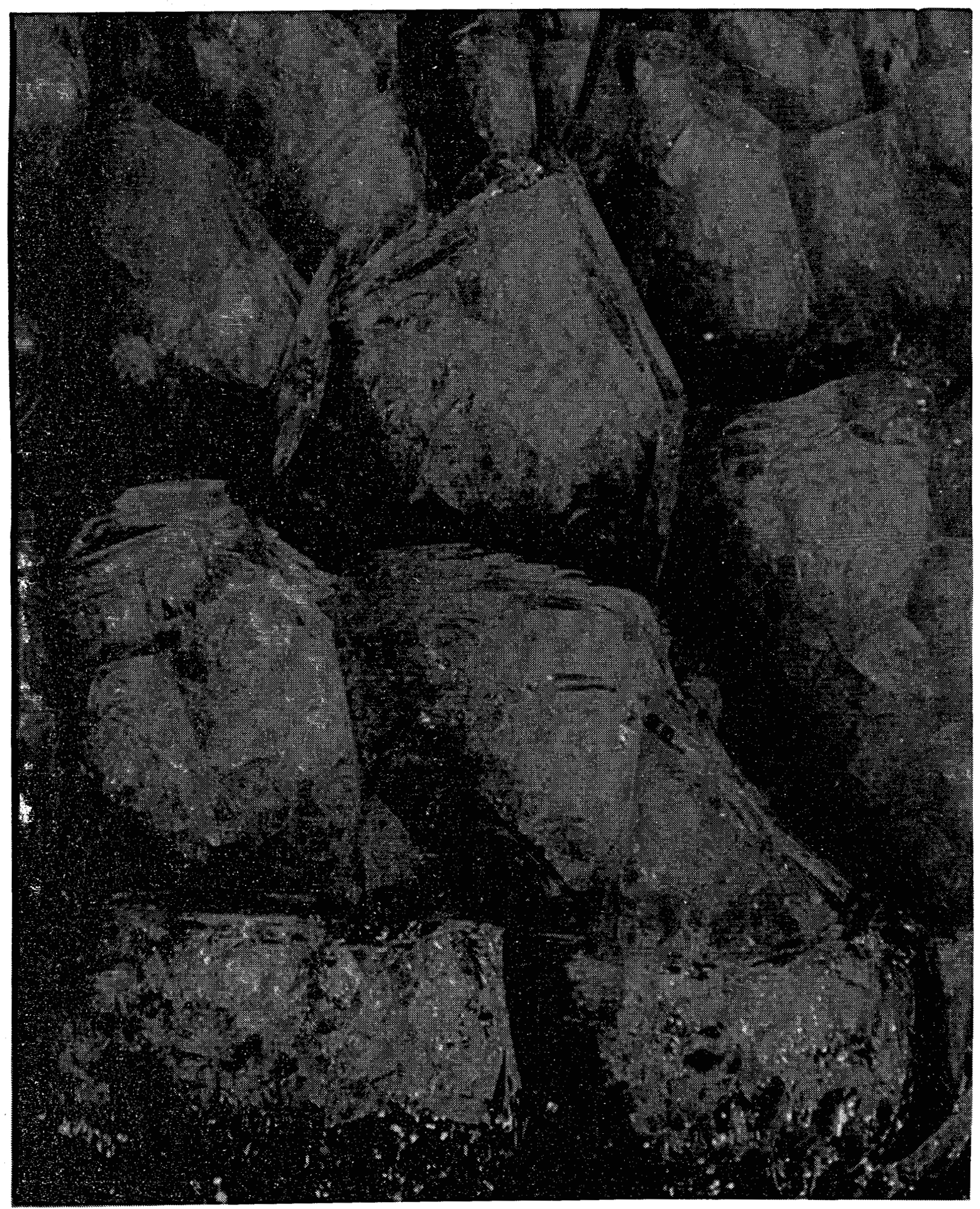

Figure 6. Close-up view of polygonal fracture pattern. 


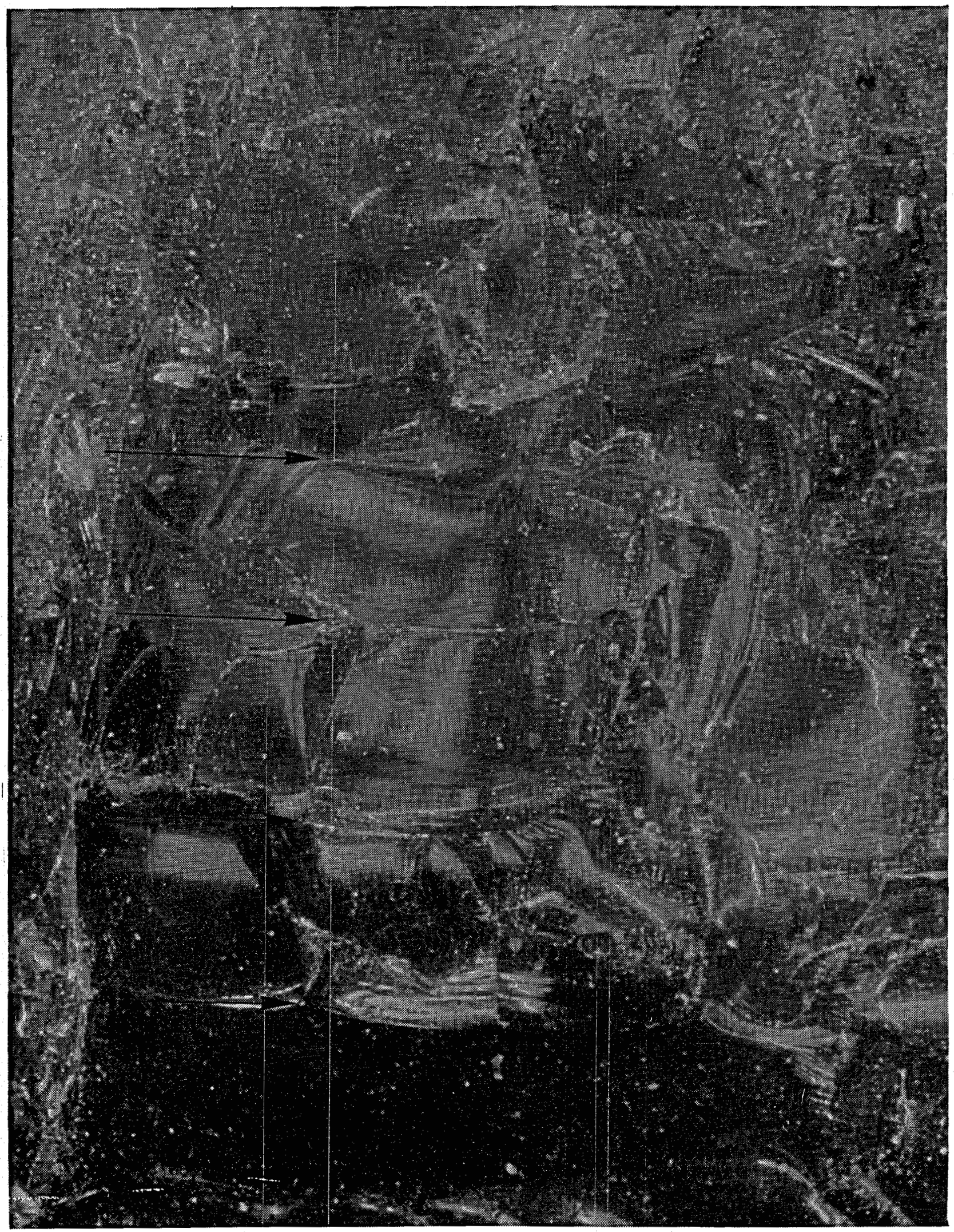

Figure 7. A cleaved open fracture face showing several generations of growth. 


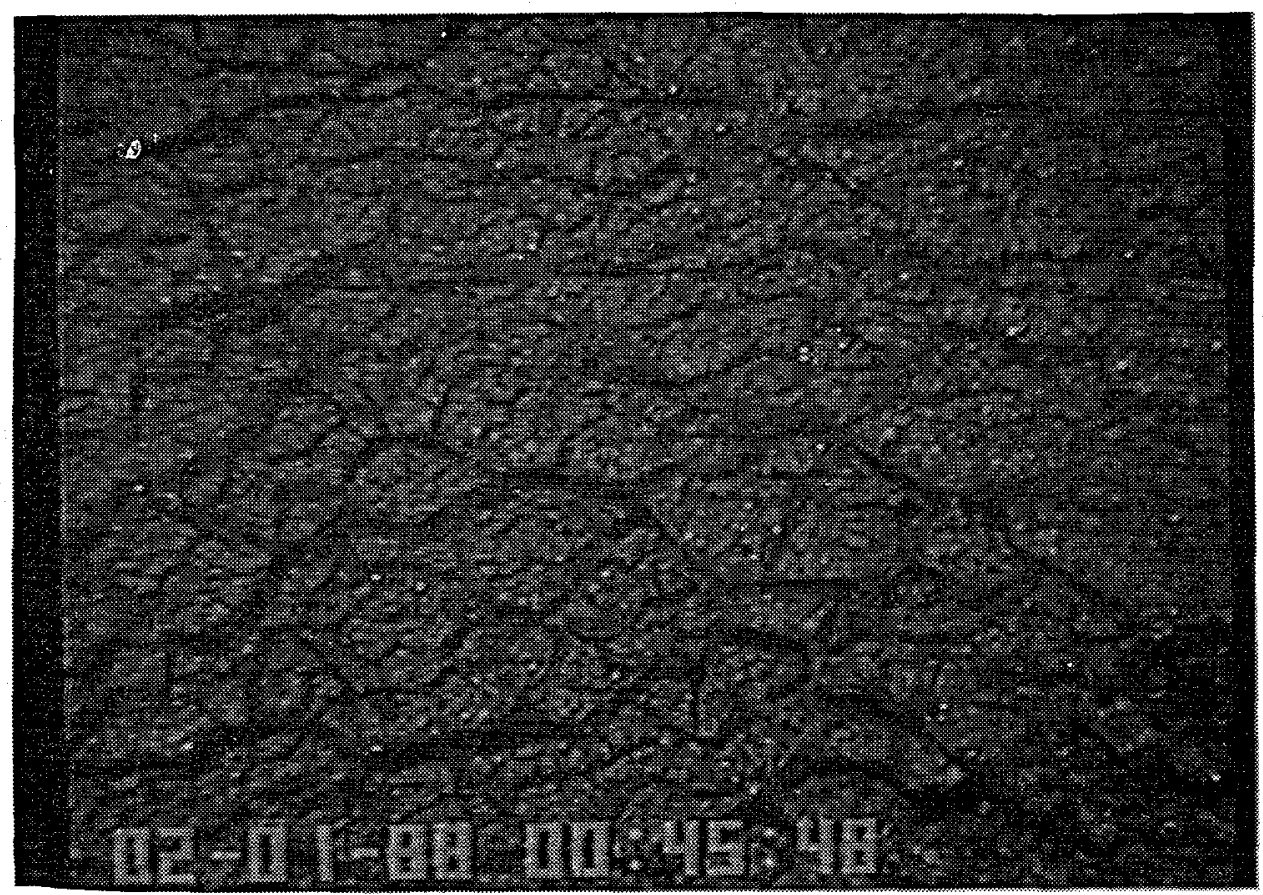

Figure 8. Fracture pattern showing several generations of fracture growth. 
is a fracture pattern with several generations of fracture cells. This selective growth pattern appears to be a three dimensional manifestation of the growth patterns of edge cooled glass plates as observed by Wemple and Longcope (1986) and Geyer and Nemat-Nasser (1982).

Drilling into magma is based on the "solidifying while drilling" concept, Figure 9. Experiments using the simulant resin were conducted to demonstrate this concept.

A three-1iter melt at $160^{\circ} \mathrm{C}$ in a four-liter glass test vessel was prepared in a furnace. At the start of the experiment, the test vessel was placed on the table of a drill press and water mist was sprayed onto the surface of the melt, forming a thin solid crust. With the crust as a barrier, one liter of water was poured over the melt. Within twenty minutes, a $3 \mathrm{~mm}$-thick crust formed, separating the melt from the water on top. A $10-\mathrm{mm}$ and a $13-\mathrm{mm}$ standard machining drill were used in the experiment. As the drill bit advanced, water followed into the hole and chilled and solidified the molten material in front of and around the drill bit. The solidified material appeared as a halo in front of the drill bit, and a fracture front was observed in the halo region ahead of the advancing drill bit. The drill was in contact with solid at all times, and the material removed was in the form of machining chips. At times when the rate of drilling became too fast, a small break in the solidified material near the tip of the drill bit would occur, and a stream of water droplets would leak out into the melt. As the droplets rose, they traced out the outline of the solidifled region around the borehole, see Figure 10, Note the fuzzy outline of the borehole as a result of fine fracturing around the borehole.

Fluid Circulation and Heat Transfer in Fractured, Solidified Magma

As a first approximation to heat transfer within the open heat exchanger, the solidified and fractured region surrounding the borehole can be modeled as a porous medium with local thermal equilibrium between the solid and the fluid phases. The porous medium is characterized by its effective permeability, $k$, and the effective saturated thermal conductivity, k. Estimates for the permeability were obtained using cubic fracture model of Snow (1968) with the fracture geometry prediction of Wemple and Longcope (1986).

Flow and heat transfer within the porous annular region is described by the standard Darcy formula for porous media. For thermally full-developed flow, the temperature profile is identical to the conduction profile, and the mean Nusselt numbers can readily be calculated as functions of the inner $\left(r_{1}\right)$ to outer $\left(r_{0}\right)$ radius ratio (r*). These fully developed Nusselt numbers are then used in the energy extraction code MAGMAXT (see later sections).

Various effects can alter the heat transfer within the porous annulus and significantly affect the net energy extraction. The most 


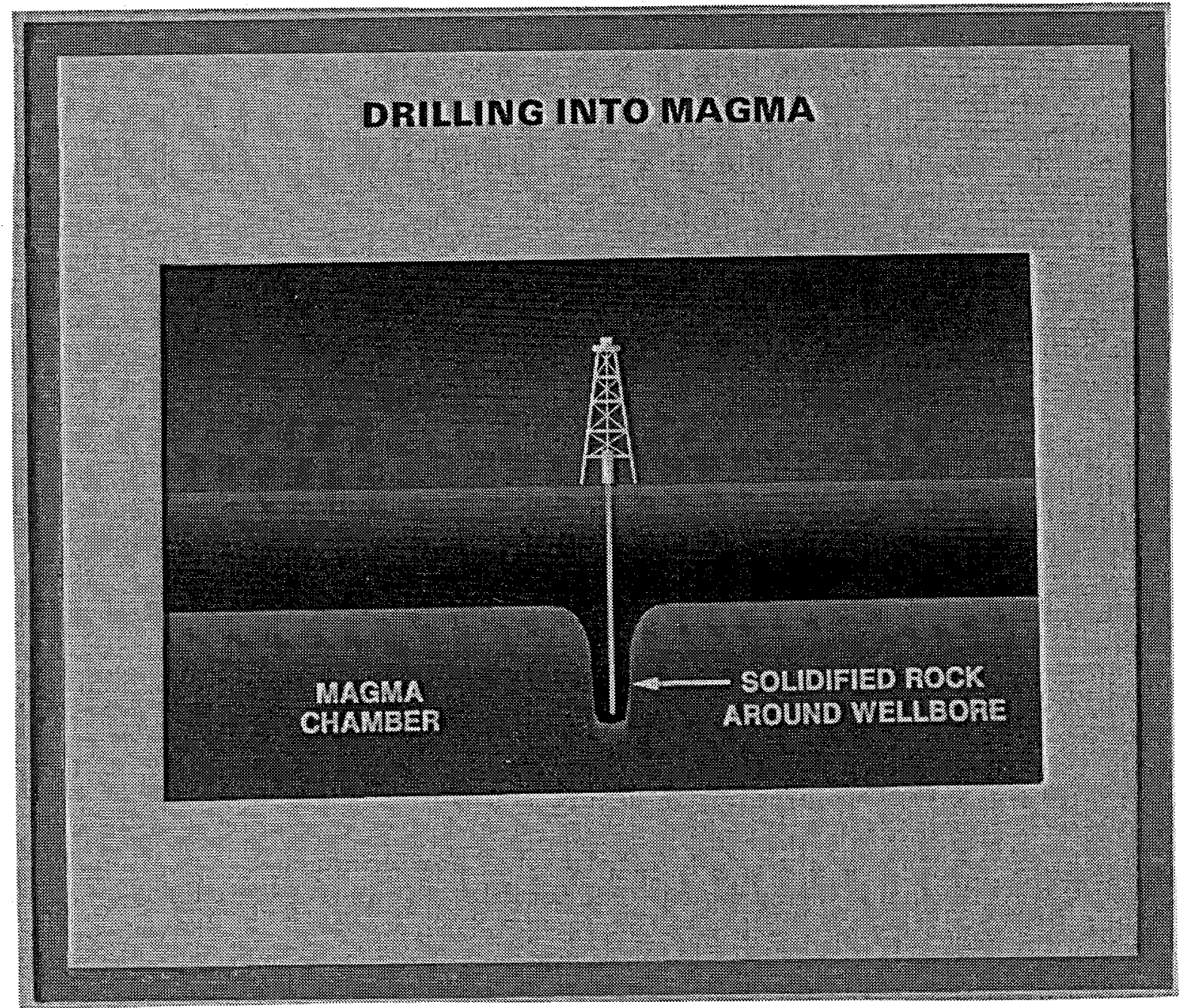

Figure 9. Conceptual representation of drilling into magma. 


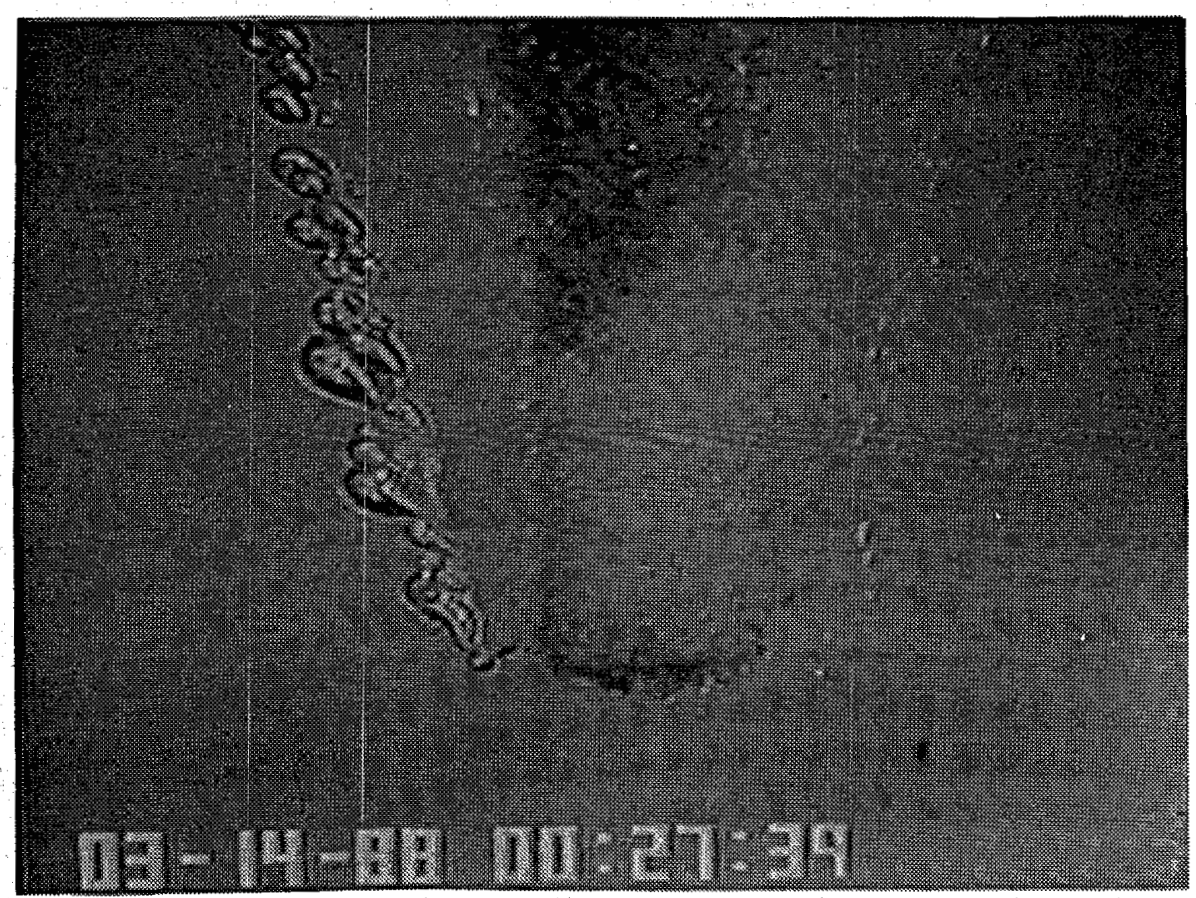

Figure 10. The extent of solidification around a borehole traced out by using water droplets. 
important effect is the developing flow or entrance effect. Heat transfer can be orders of magnitude higher near the entrance than the fully developed values far downstream. The developing thermal field for uniform (slug) flow in an annular region (the fractured and solidified volume around the borehole), may be calculated by direct analogy to the problem of transient cooling of an annular shaped billet. For the case of an insulated inner boundary and a constant temperature outer boundary, the solution for the temperature is given by Carslaw and Jeager (1959). The results of the analysis are depicted in Figure 11 for the case of $r *=0.01$ (a reasonable value for the radius ratio of the borehole and the solidified volume surrounding it). Two results from this analysis are of interest. First, the mixed mean Nusselt number in the entry region is much higher than its asymptotic (fully developed) value. Second, this calculation indicates that the fully-developed thermal conditions may. not be attained for the expected length of heat exchanger volume. The net result is that the overall heat transfer coefficient corresponding to flow through the heat transfer volume can be expected to be two to five times higher than the conservative fully-developed estimates.

The porous flow analogy of the heat transfer in the fractured heat transfer volume is also being studied experimentally at the University of Utah (Clarksean et al, 1988). In addition to the entrance flow effect, the experimental program also addresses the buoyancy effect due to the large temperature difference between the inner surface (borehole) and the outer surface (magma) of the heat transfer volume. The experimental apparatus uses an annular space formed between two concentric pipes having diameters of $3.2 \mathrm{~cm}$ and $29.2 \mathrm{~cm}$. The space is filled with either $1 \mathrm{~mm}$ ceramic microspheres or glass spheres to form a porous bed. Water is injected at the base of the column either as a uniform (slug) flow or as a source flow (simulating injection at the base of the heat transfer volume). The outer wall boundary condition can be adjusted to be either uniform temperature or uniform heat flux. Figure 9 shows the design of the experimental apparatus. Radial temperature distributions at different axial locations for two experiments are shown in Figures 13 and 14. Local heat transfer coefficients inferred from such data are shown in Figure 15 as a function of flow rate. The data show clearly the trend of high heat transfer coefficient near the entrance decreasing with axial distance. Average heat transfer coefficients are developed from this type of data to examine the effect of buoyancy. An example of this is shown in Figure 16 for two wall heat fluxes in plots of Nusselt number, Nu versus the ratio of Peclet number to the Rayleigh number, $\mathrm{Pe} / \mathrm{Ra}$. High values of this ratio indicate the dominance of forced convection. As the ratio decreases, increasing effects of natural convection result in a leveling off (rather than decreasing) of the Nusselt number. Current work comparing the experiments with numerical simulations is finding very good agreement. The numerical code is expected to be useful in extrapolating results to downhole magma environments. 


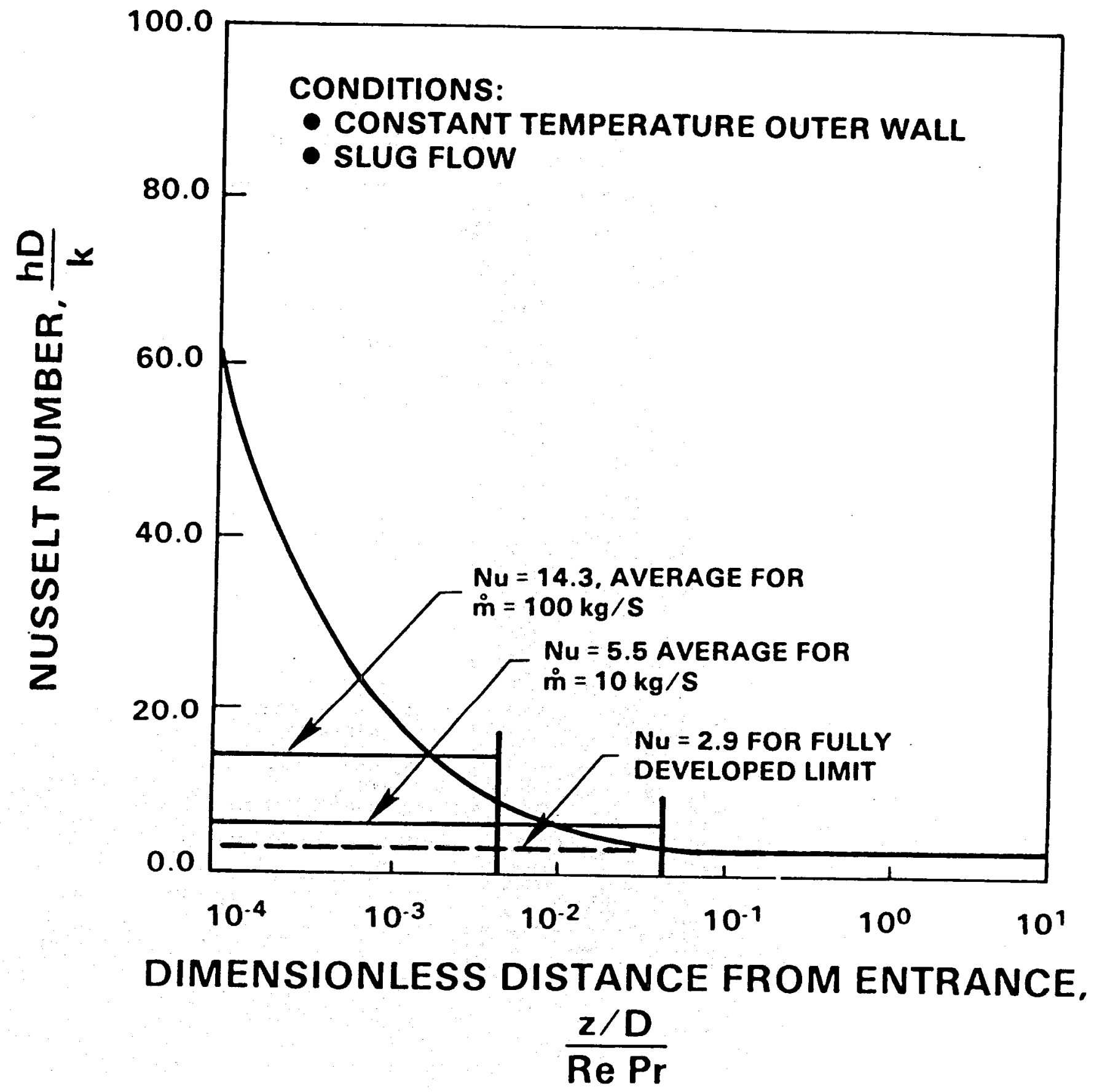

Figure 11. Computed nusselt number showing entry length effects. 


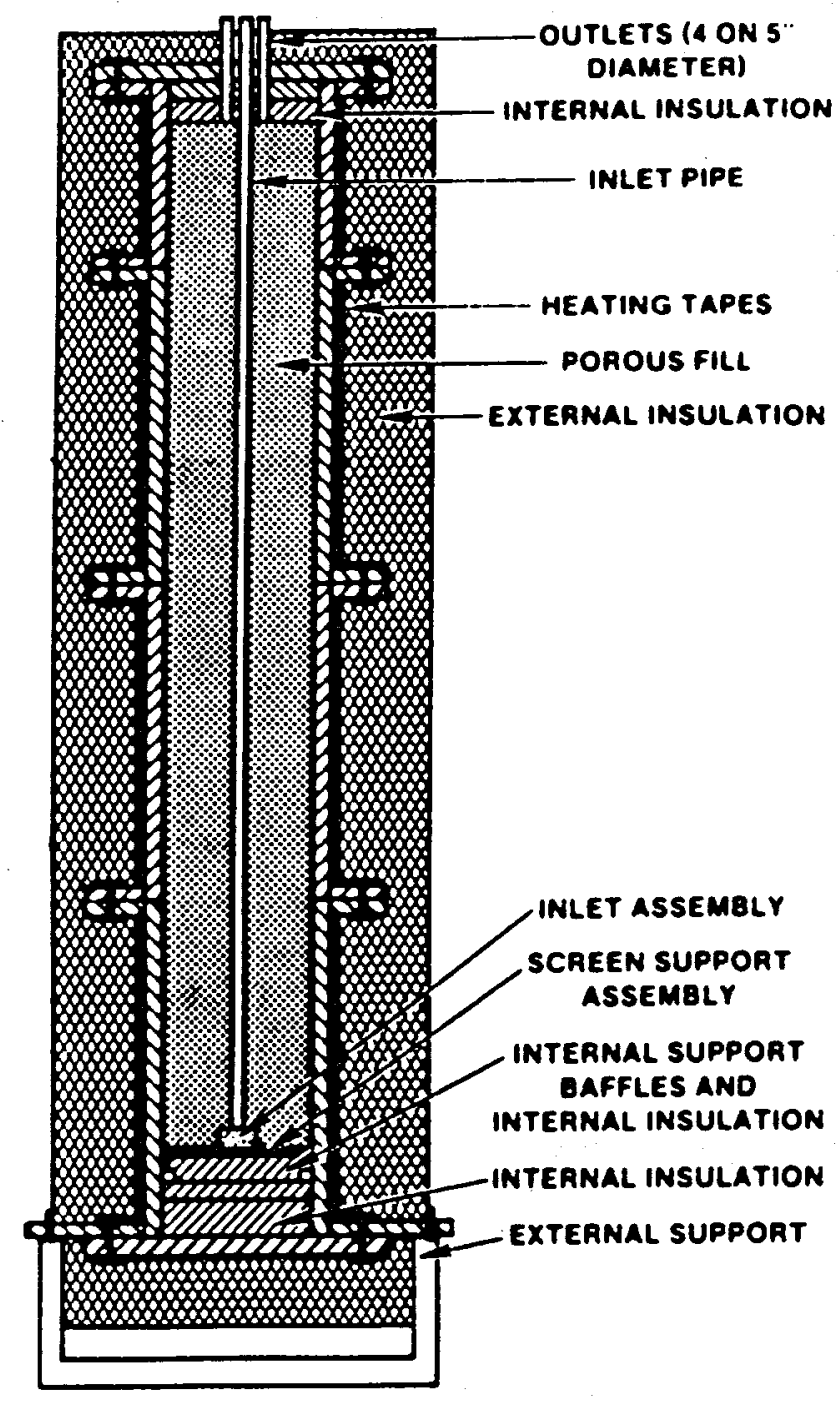

Figure 12. Cross-section of open heat exchanger experimental apparatus. 


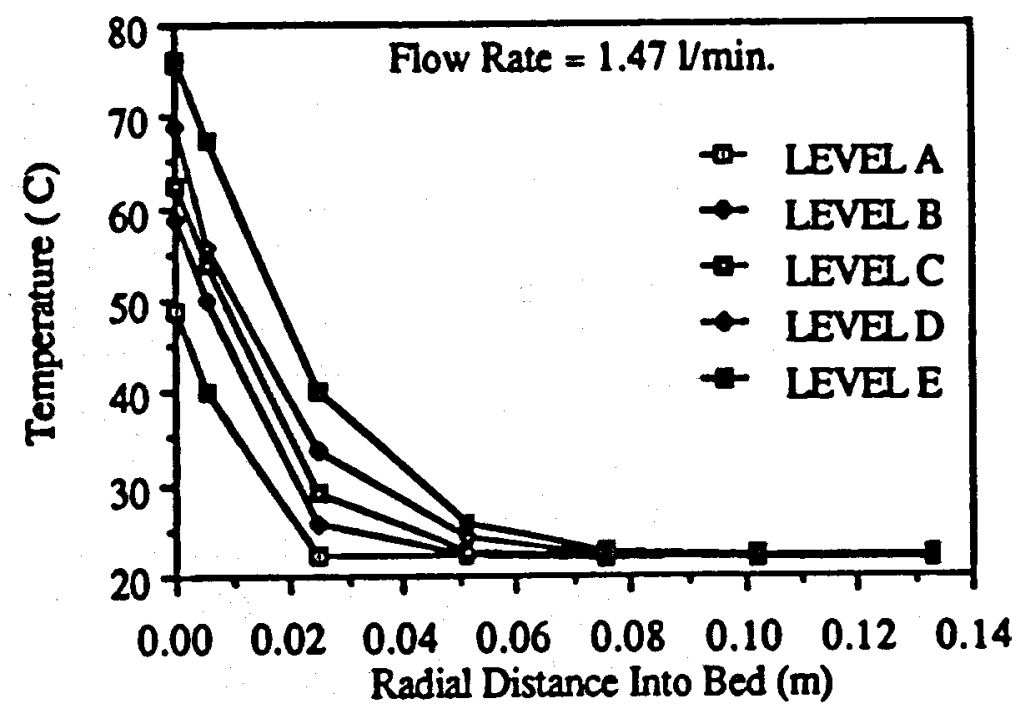

Figure 13. Measured temperature vs. radial distance in bed constant heat flux, glass beads, flow rate $=1.471 / \mathrm{min}$.

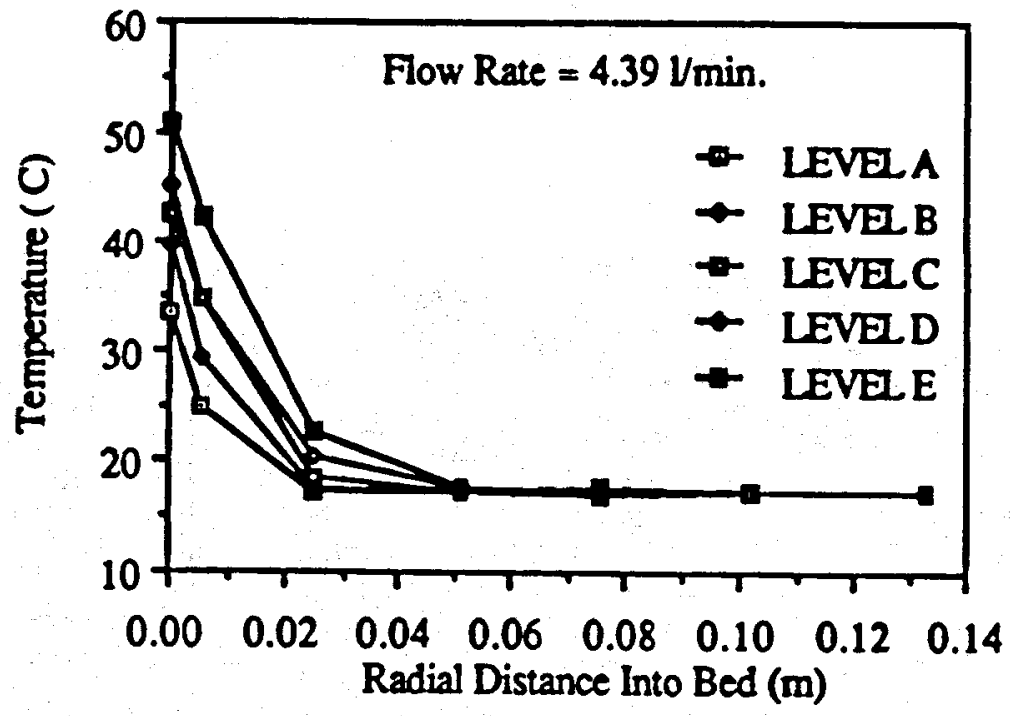

Figure 14. Measured temperature vs. radial distance into bed constant heat flux, glass beads, flow rate $=4.391 / \mathrm{min}$. 


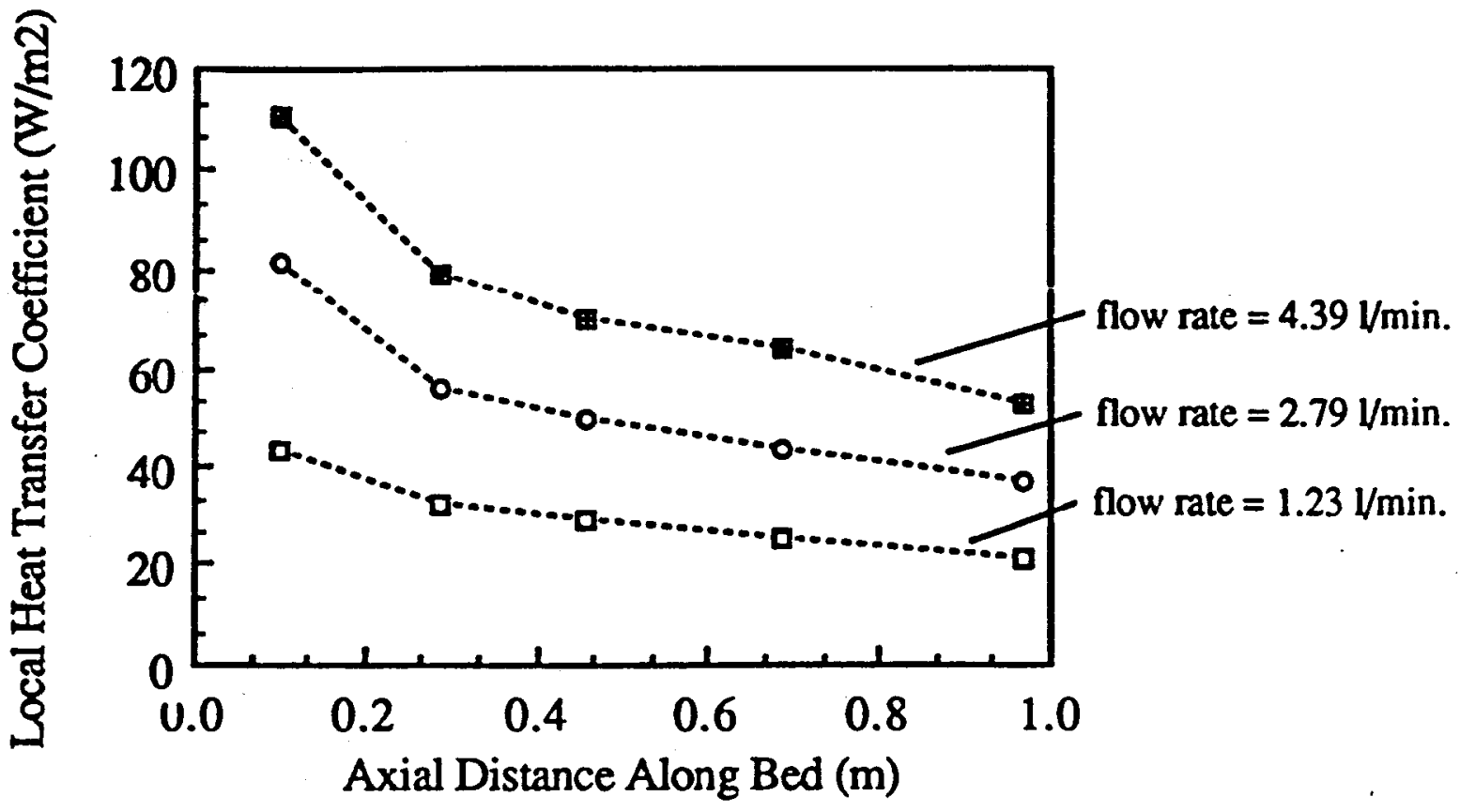

Figure 15. Calculated local heat transfer coefficient based on measured temperature, constant heat flux, glass beads.

Representative Local Heat Transfer Coefficients. Constant Heat Flux, Glass Beads.

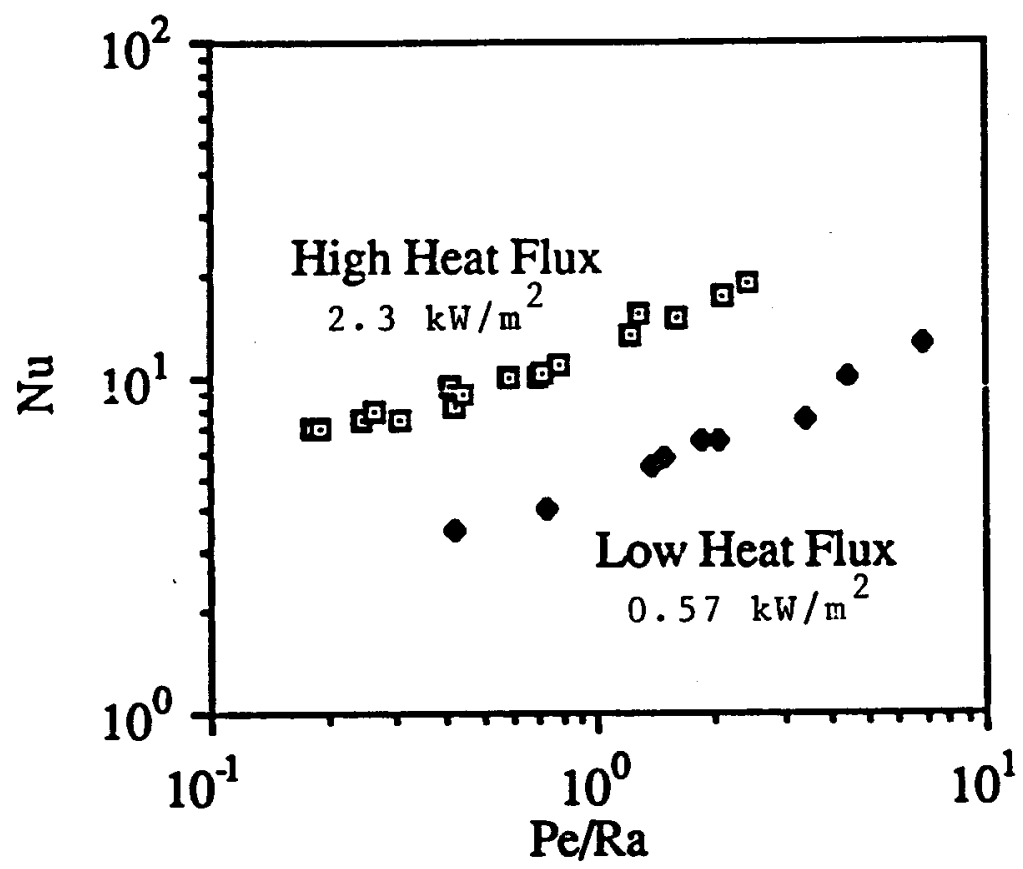

Figure 16. Calculated $\mathrm{Nu}$ vs. Pe/RA, based on measured temperatures; constant heat flux, glass beads. 
Convective Flow and Heat Transfer in Molten Magma

As shown in Figure 4, the direct contact heat exchanger is surrounded by convecting molten magma. The rate of energy extraction ultimately depends on the convective heat transfer between the molten magma and the solidified magma comprising the direct-contact heat exchanger. It is, therefore, important to understand the convective transport in a magma chamber and the interaction between the global convection in the chamber and the convective flow around the heat exchanger. A typical representative length scale of a magma chamber may be taken as $5 \mathrm{~km}$ with a magma temperature ranging from $650^{\circ} \mathrm{C}$ to $900^{\circ} \mathrm{C}$. The representative chamber Rayleigh number is then calculated to be of the order of 1016; the flow is 1ikely to be highly time dependent at such high Rayleigh numbers. The problem is further complicated by the extremely large variations (by several orders of magnitude) of viscosity of the molten magma as a function of temperature. There is very little information available from existing heat transfer literature on such flow. Extrapolation from a variable viscosity, correlation indicates that with three orders of magnitude change of viscosity, the heat transfer can be a factor of 2 to 3 lower than the constant-viscosity case.

A study is underway to gain an understanding of convective transport in a magma chamber. The approach taken in the study is to first characterize the convection in a magma-like material and then to examine the convective heat transfer to an energy extraction device inserted into the magma chamber, Figure 17. Typically, a magma chamber is periodically replenished at a discrete location. Hence, we elect to investigate the convection flow in an enclosure with localized heating from below. The present study involves both laboratory experiments and computer modeling. Results thus far cover only the laminar flow regime (Chu and Hickox, 1988). It is important to realize that we are not attempting to exactly duplicate the flow in a magma body, but rather to develop the confidence in the computer model to analyze such flows.

The experimental apparatus consists of a Lexan enclosure with a square planform measuring $56 \mathrm{~cm}$ on a side, Figure 18. A heated strip measuring $13.6 \mathrm{~cm}$ by $56 \mathrm{~cm}$ is centered on the lower inside surface of the enclosure. The depth of the fluid layer for the results reported here is set equal to the width of the heated strip. The enclosure, therefore, has essentially a four to one width-to-depth ratio. The top of the layer is maintained at a constant temperature by a watercooled plate. The large viscosity variation characteristic of molten magma is simulated with a commercial $42 / 43$ corn syrup. The experiments covered top-to-bottom viscosity contrasts (ratios) ranging from 3 to 1400. In addition to the measurement of overall heat transfer between the heated strip and the top surface, velocity and temperature distributions were obtained. The velocity field was mapped by taking time exposure photographs of light scattered from seeded particles illuminated by a sheet of light from a He-Ne laser. The temperature field was mapped using a thermocouple probe. 

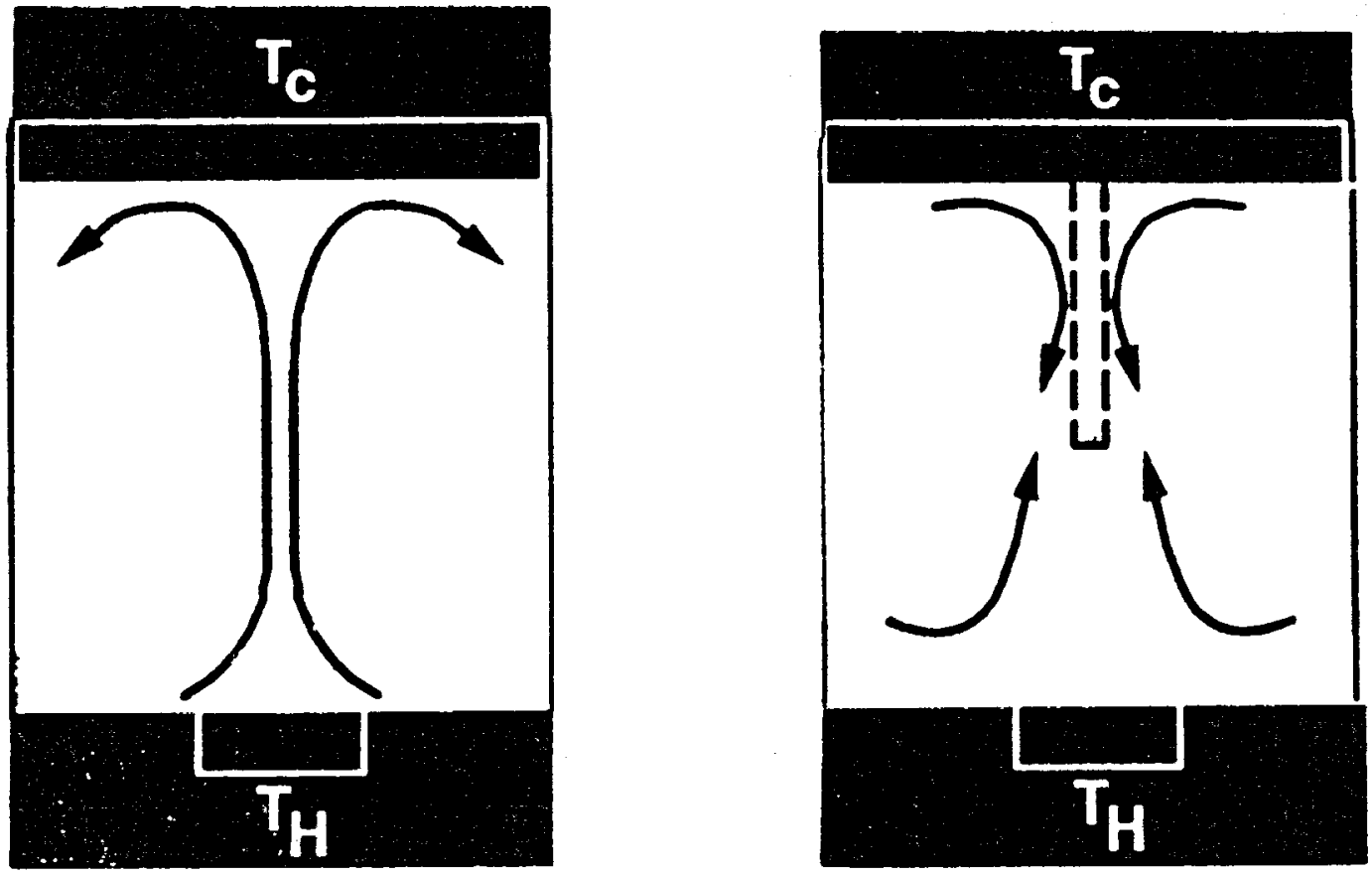

Figure 17. Configurations for magma convection experiments.

A. Base case.

B. Convection around an energy extraction device. 


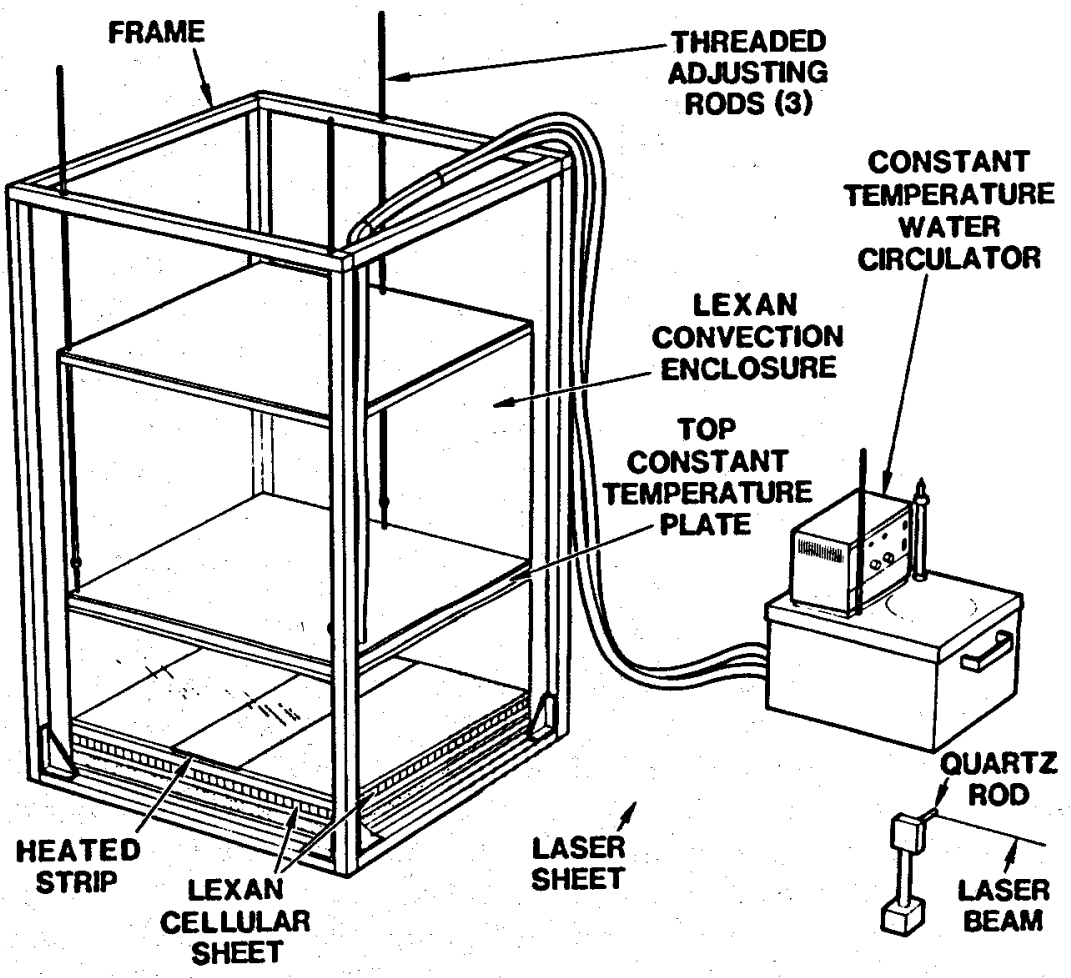

Figure 18. Schematic of magma convection experiment. 
The experiment is numerically simulated through the use of a state-of-the-art finite element computer program (FIDAP User's Manual, 1988). Shown in Figure 19 is a typical isotherm pattern and a comparison between numerically and experimentally obtained streamline patterns. The flow is laminar and steady; it is characterized by two counter rotating cells driven by a plume rising from the heated strip. General agreement is demonstrated between predictions and flow visualization. Detailed comparisons between prediction and experiment of the vertical velocity profiles and axial temperature distributions of the rising plume are shown in Figure 20. The agreement is very good over the entire range of viscosity variations.

Temperature and velocity distributions from the experiments and numerical simulation both show that the effect of large viscosity variation is mainly confined to a stagnant conduction layer next to the cold surface; the rest of the flow field is quite similar to an iso-viscous flow. Similar observations were also made by Carrigan (1987) in his recent theoretical study of magmatic convection. As a result, the heat transfer from the heated strip is found to be well correlated by a conventional iso-viscosity correlation with a viscosity contrast correction, Figure 21. In this correlation, the largest effect of viscosity variation is accommodated by evaluating properties at the mean temperature of the top surface and the heated strip. The additional power law correction based on the viscosity contrast is relatively small. The correction for a viscosity contrast of $10^{3}$ is less than 308, rather than a factor of 2 to 3 as predicted by extrapolation from existing correlations. The result is quite remarkable because it indicates, at least in laminar flow, that isoviscous heat transfer correlations can give reasonable results to flows with extremely large viscosity variations. While the configuration is different for an energy extraction device in a magma chamber, we feel the heat transfer and flow field will still exhibit the same general behavior, and the viscosity correction law still applies. Experiments are currently underway with greater fluid depth (higher Rayleigh number) and incorporating an energy extraction device protruding from the top of the enclosure.

\section{Numerical Simulation of single-well energy extraction}

A numerical code called MAGMAXT (Ortega, 1988) has been developed to simulate the flow of compressible, homogeneous water/vapor within the well and heat exchanger with heat transfer to and from the convecting magma and the overlying formation. The code allows arbitrary specification of a contiguous flow path through regions such as tubing, concentric pipe annulus, or the heat exchanger. Heat transfer to or from the fluid stream is allowed through the specification of overall heat transfer coefficients between the counterflowing fluid streams and between the fluid and formation or magma. Heat transfer is assumed to occur in the radial direction only. Convective heat transfer coefficients within the tube or annulus are evaluated assuming fully-developed turbulent flow using commonly available correlations for single or two-phase flow. 


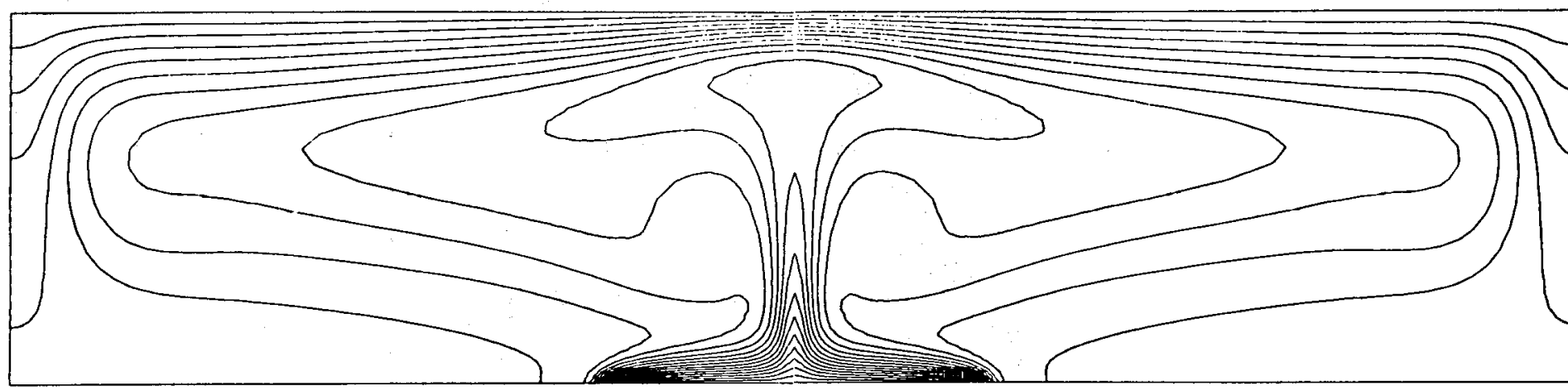

ISOTHERMS
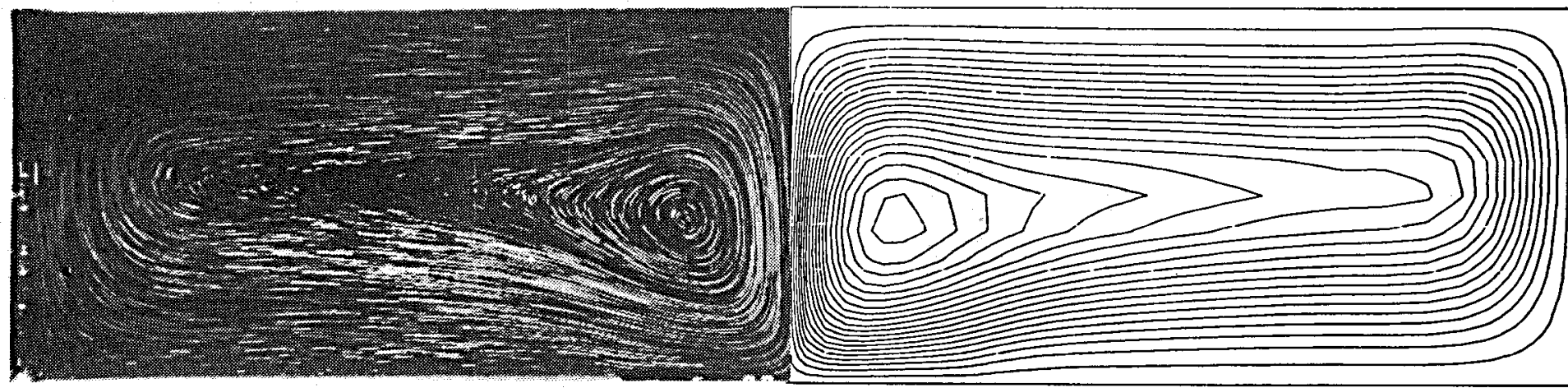

STREAMLINES

Figure 19. Isotherms and Streamlines for Case A (See Figure 20 for experimental parameters). 

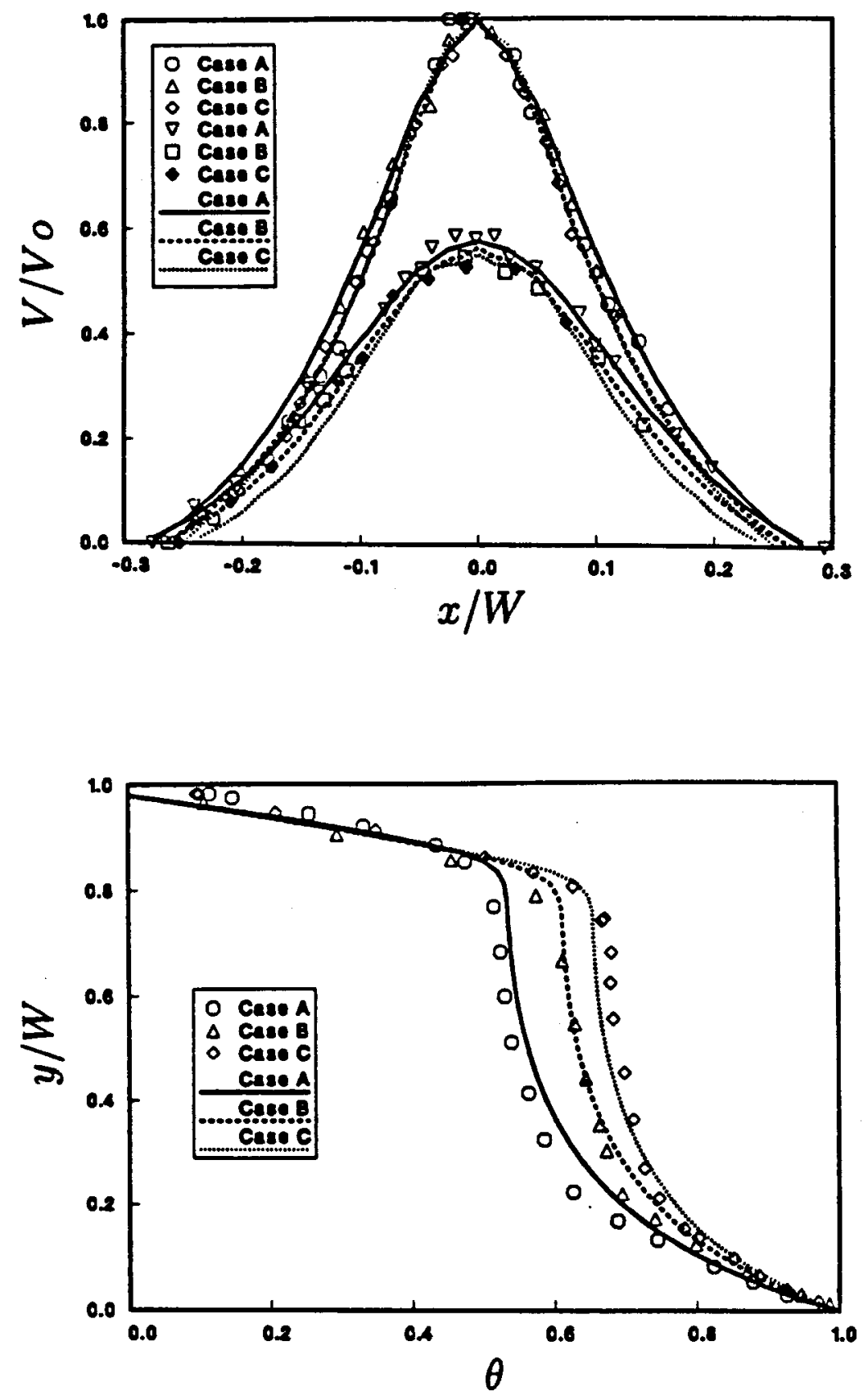

\begin{tabular}{|c|c|c|c|c|c|c|c|c|c|c|}
\hline Cace & $T_{\bullet} \cdot \vec{C}$ & $\begin{array}{l}\Delta T \\
C\end{array}$ & $\begin{array}{l}R a_{0} \\
\times 10^{-4}\end{array}$ & $\begin{array}{r}R a_{m} \\
\times 10^{-1}\end{array}$ & $\begin{array}{r}P r_{0} \\
\times 10^{-1}\end{array}$ & $\begin{array}{r}\mathrm{Pr}_{\mathbf{m}} \\
\times 10^{-6}\end{array}$ & $\mu_{0} / \mu_{n}$ & $k_{*} i k_{n}$ & $c_{0} / C_{A}$ & $\rho_{0}^{\prime} \rho_{n}$ \\
\hline A & 29.2 & 20.5 & 6.08 & 21.7 & 2.5 & 0.73 & 9.9 & 0.08 & 0.97 & 1.01 \\
\hline B & 15.6 & 37.0 & 1.38 & 20.1 & 19.78 & 1.37 & 101.3 & 0.97 & 0.95 & 1.02 \\
\hline & 5.3 & 51.9 & 0.28 & 19.4 & 134.39 & 1.96 & 1026.0 & 0.96 & 0.92 & 1.02 \\
\hline
\end{tabular}

Table 1. Parameters for the three cases simulated.

Figure 20. A. Measured and computed velocity distributions in the plume region.

B. Measured and computed temperature distributions along with vertical center plume of the enclosure. 


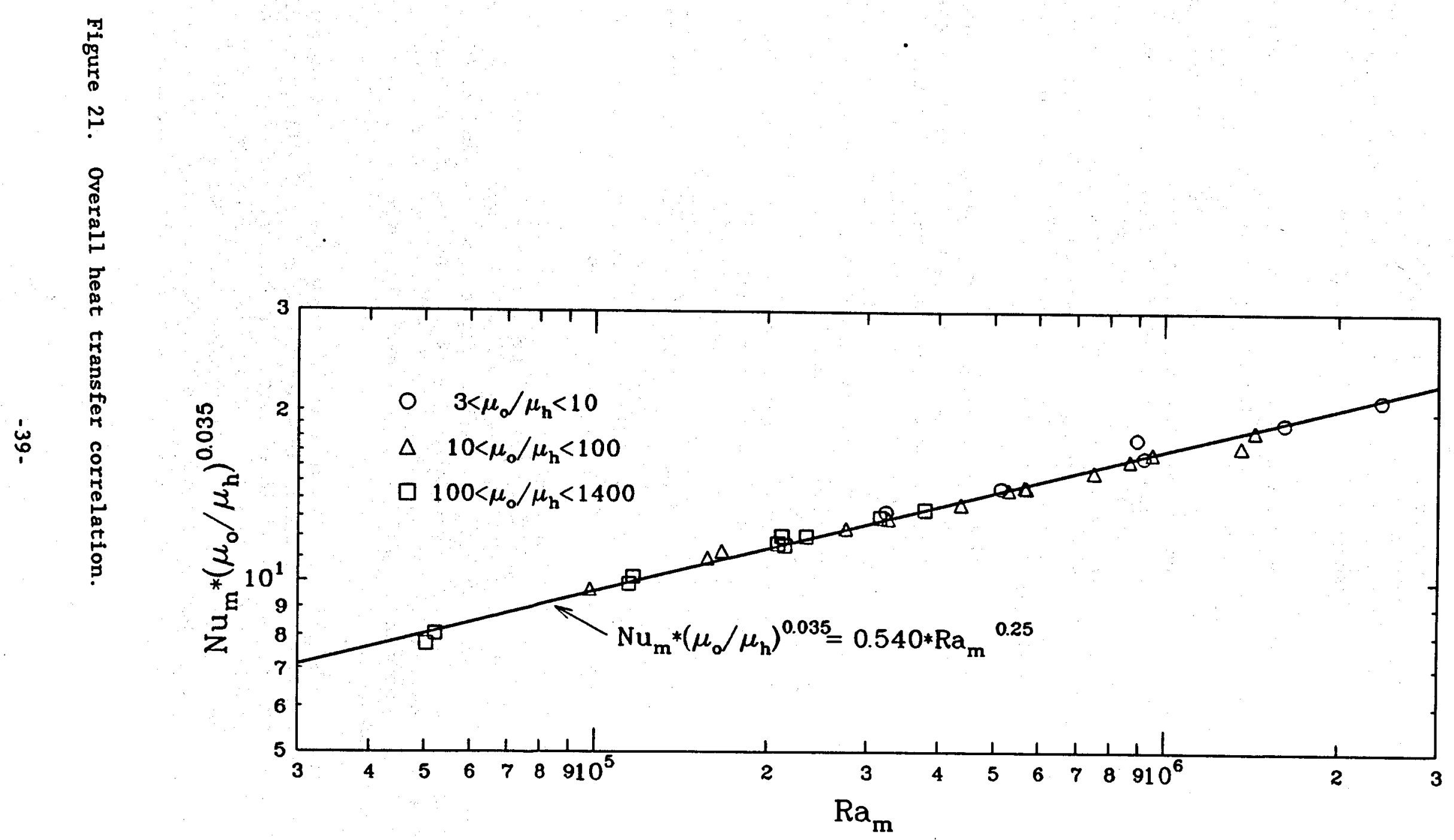


Separate correlations are used in the sub-cooled, saturated, superheated and super-critical regions. The overlying formation is assumed to be homogeneous, with constant properties, and conduction to the formation is modeled using the quasi-steady assumption of Ramey (1962).

MAGMAXT has been used to simulate the flow and energy extraction rate for a well with a 0.194-m-diameter and an insulation thickness of $1.5 \mathrm{~cm}$ on the injection tube. The well depth is $5 \mathrm{~km}$ followed by a 1 $\mathrm{km}$ heat exchange depth in molten magma. The open heat exchanger is assumed to be a porous annulus whose outer diameter can vary depending on the heat exchange rate. The temperature of the plastic zone around the heat exchanger is maintained at a constant $900^{\circ} \mathrm{C}$, and the available heat flux from the convecting magma is specified at $1 \mathrm{~kW} / \mathrm{m}^{2}$. By specification of the injection pressure and mass flow rate, the flow state throughout the circulation path can be computed in an iterative marching procedure by MAGMAXT.

Results shown in Figures 22 through 26 are calculated assuming fully developed Darcy flow in the fractured solidified magma comprising the open direct-contact heat exchanger. Because the MAGMAXT code uses fully developed Darcy flow correlations to calculate heat transfer in the fractured matrix, effects resulting in increased heat transfer over and above fully developed flow are accounted for by adjusting the effective thermal conductivity of the solidified magma/water matrix. The base case calculation uses an effective thermal conductivity of $15 \mathrm{~W} / \mathrm{m}-\mathrm{K}$, which includes entry length effects based on a mass flow rate of $100 \mathrm{~kg} / \mathrm{s}$ (see Figure 11). Two additional cases are shown for comparison: (1) the lowest limiting case, with an effective thermal conductivity of $3 \mathrm{~W} / \mathrm{m}-\mathrm{K}$, corresponding to fully developed flow resulting from very low flow rates; and (2) the enhanced case, with an effective thermal conductivity of $30 \mathrm{~W} / \mathrm{m}-\mathrm{K}$, corresponding to very high flow rates. In the following discussions, attention will be focused mainly on the base case.

Figure 22 shows the temperature of the circulating water at a flow rate of $50 \mathrm{~kg} / \mathrm{s}(800 \mathrm{gal} / \mathrm{min})$ for the base case. The flow path is specified as down the wellbore annulus (A-B), down the insulated tubing in the heat exchange region (B-C), up the porous annulus (C-D), and up the insulated wellbore tubing (D-E). The temperature gain on the down-flow and the temperature loss on the return flow nearly cancel each other out. Within the heat exchanger, the net temperature increase is $600 \mathrm{~K}$.

As seen in Figure 23, the pressure increase in the injection path is due almost entirely to the hydrostatic pressure of the fluid in the sub-cooled state. As the fluid is heated in the heat exchange region, its density decreases, hence, the pressure in the return path decreases less rapidly than in the injection path. Because of the net density imbalance between the two flow paths, the flow loop has the capacity for natural thermosyphoning. In the current example, the 


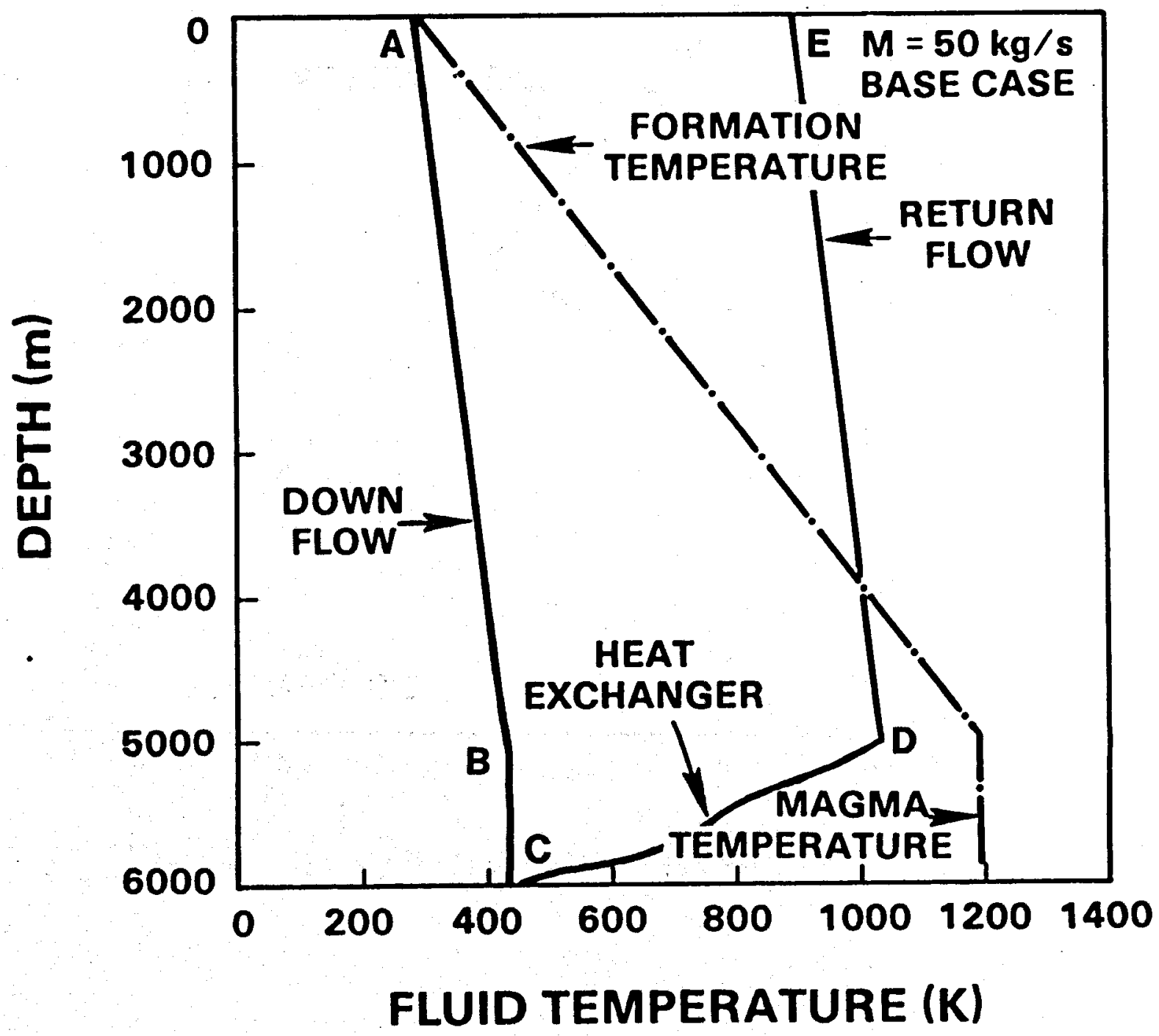

Figure 22. Fluid temperature vs. depth. 


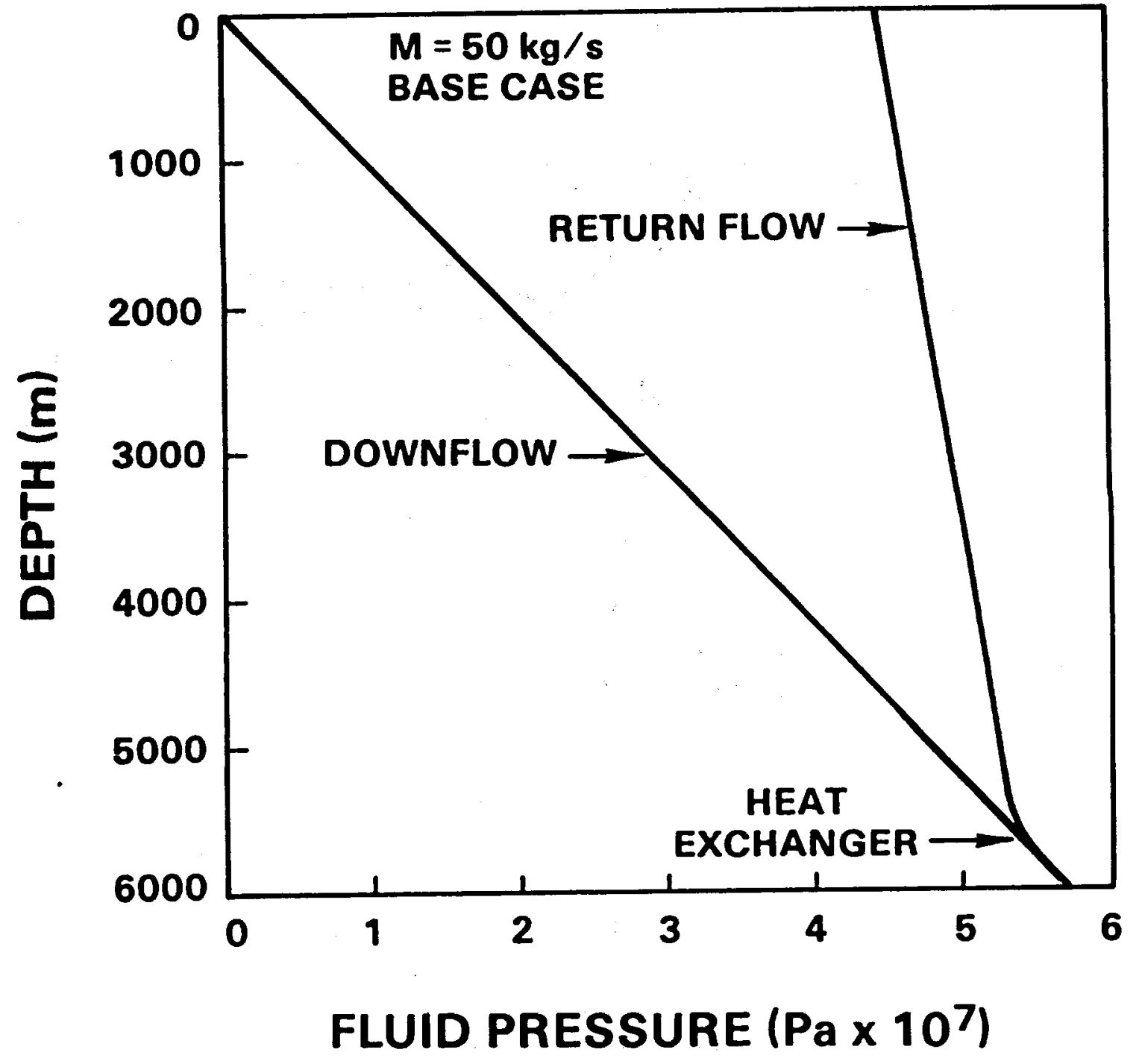

Figure 23. Pressure vs. depth. 
inlet pressure was specified as ambient, hence the well is selfflowing at a flow rate of $50 \mathrm{~kg} / \mathrm{s}$ with a wellhead pressure of roughly $44 \mathrm{MPa}$.

The Pressure-enthalpy diagram for the flow, Figure 24, illustrates the fluid phases in the loop. The hydrostatic pressure increase in the injection path results in pressures well above the critical pressure at the inlet to the heat exchanger. Because of the large flow area in the open heat exchanger annulus, the fluid is heated with very little pressure drop but with an accompanying density decrease. Depending on the flow rate and the specified wellhead back pressure, the exiting fluid state may be superheated vapor, supercritical, or highly-pressurized hot water.

The net temperature increase of the circulating water and the total extracted thermal energy are presented as a function of mass flow rate of the circulating water in Figures 25 and 26 , respectively. For both the base case and the enhanced case, in the range of flow rates of interest, the exit temperature of the water is above the critical temperature. While the total extracted thermal energy increases with flow rate, the temperature, (and thus the quality of the energy) decreases with flow rate at large flow rates. Therefore, there must exist an optimum flow rate where the net usable energy is maximum. Details of this consideration are covered in the section on thermodynamic system analysis.

FY88 Milestones - The following summary presents the status of each FY88 milestone under this activity:

* Complete basic magma chamber convection experiment $(6 / 88)$

The milestone was modified during the course of the investigation. The original experiment called for two depth-to-width aspect ratios: 1-to-4 and 1-to-1. The 1-to-4 aspect experiment was completed on time. The results were reported in two conference papers (both conferences were in FY89). The 1-to-1 aspect ratio experiment was delayed in favor of some transient flow development studies that are of general geophysical interest. The transient flow development results were reported at the ASME National Heat Transfer conference in August 1988. The 1-to-1 aspect ratio experiment was initiated in this reporting period. In addition, hardware for energy extraction simulation experiment was designed and fabricated. Both experiments are expected to be completed in FY89.

* Report result of secondary fracturing experiments $(8 / 88)$

The task for this milestone was modified to the study of thermal stress fracturing using low-temperature simulant. The original task was listed because our simple thermal stress fracturing model predicted a fracture pattern with closely spaced horizontal fractures and few vertical fractures to achieve a three dimensional network. Secondary fractures from the horizontal fractures would then play an 


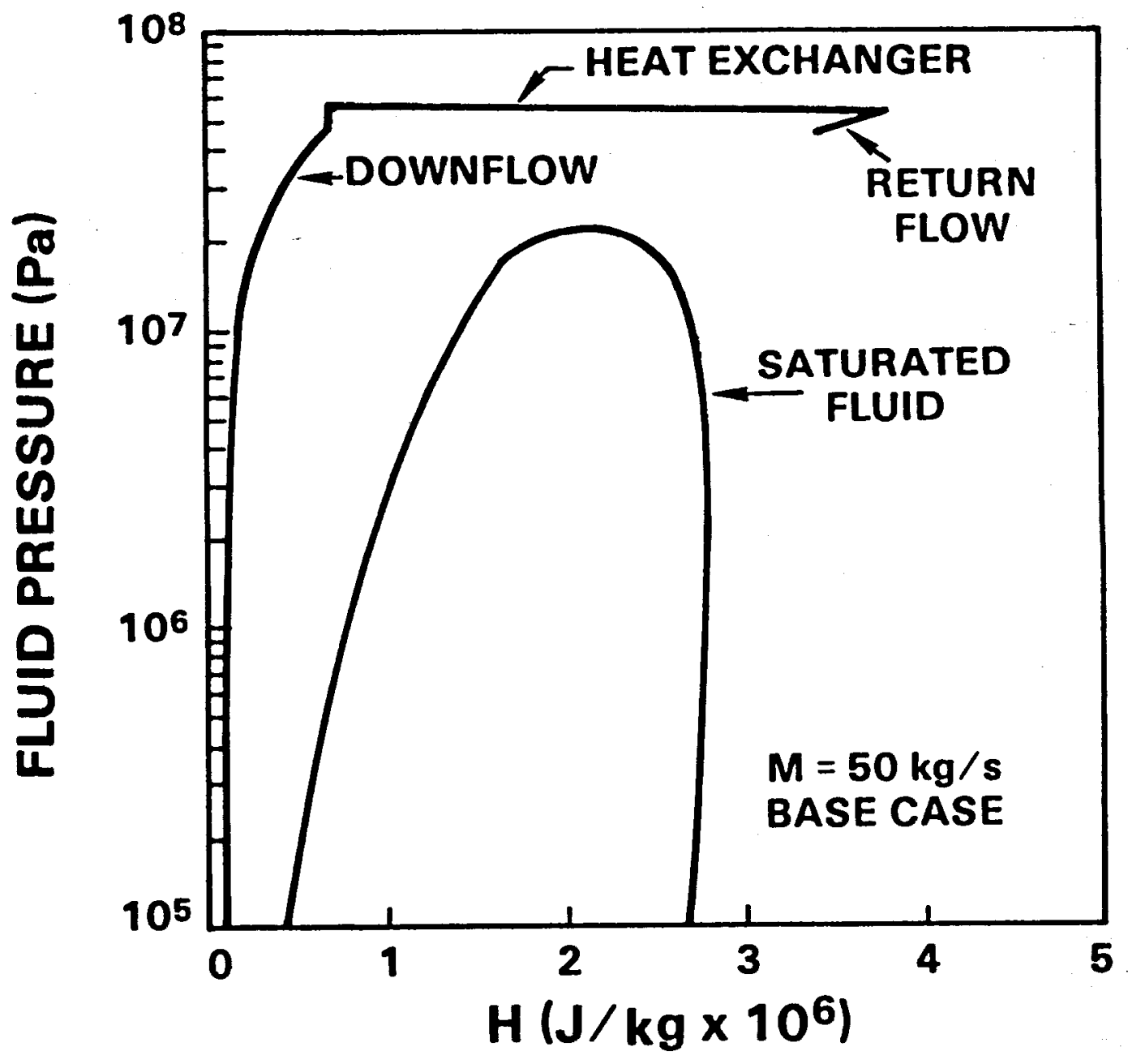

Figure 24. Pressure vs. enthalpy. 


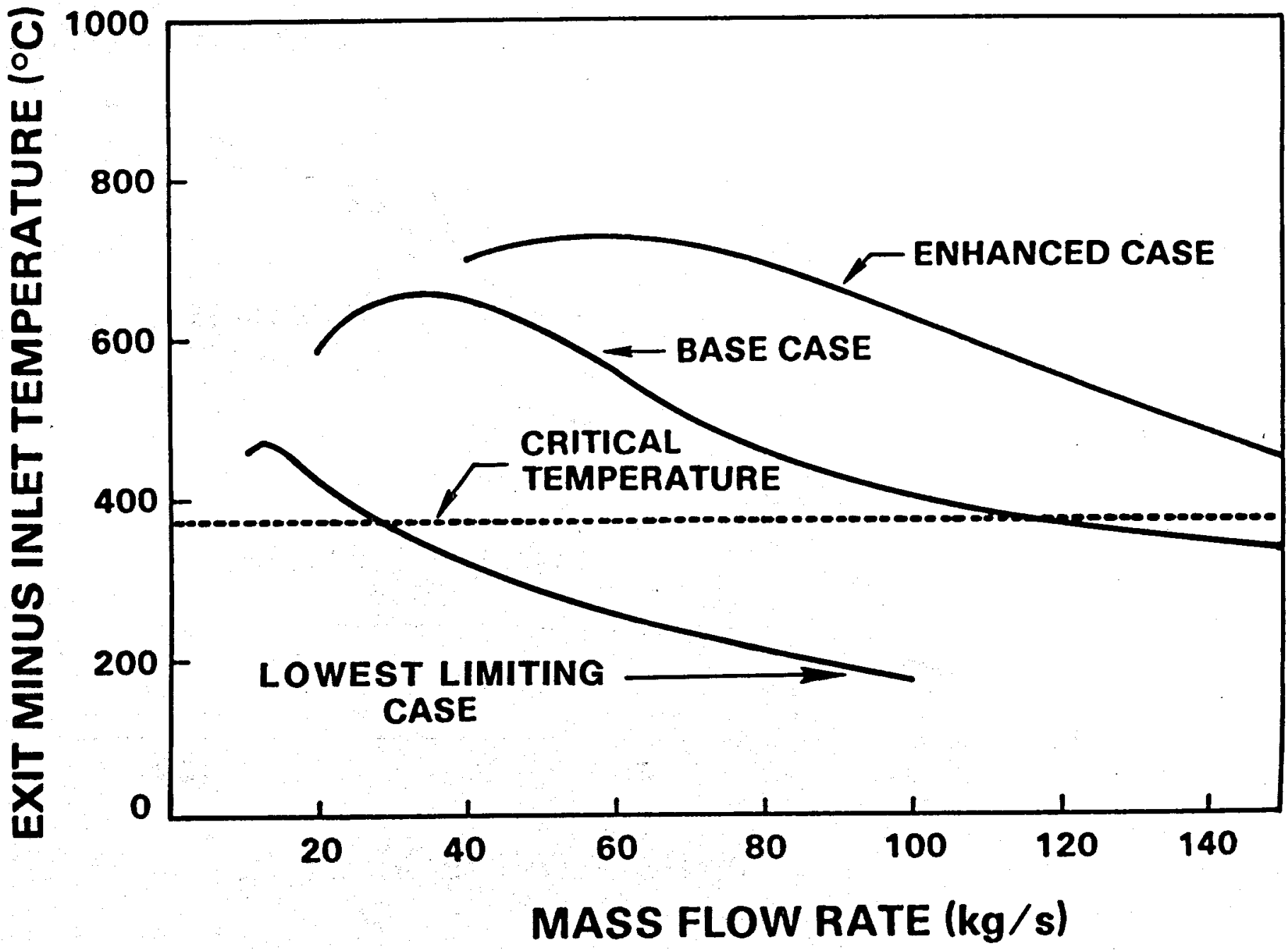

Figure 25. Temperature increase of circulating water vs. mass flow rate. 


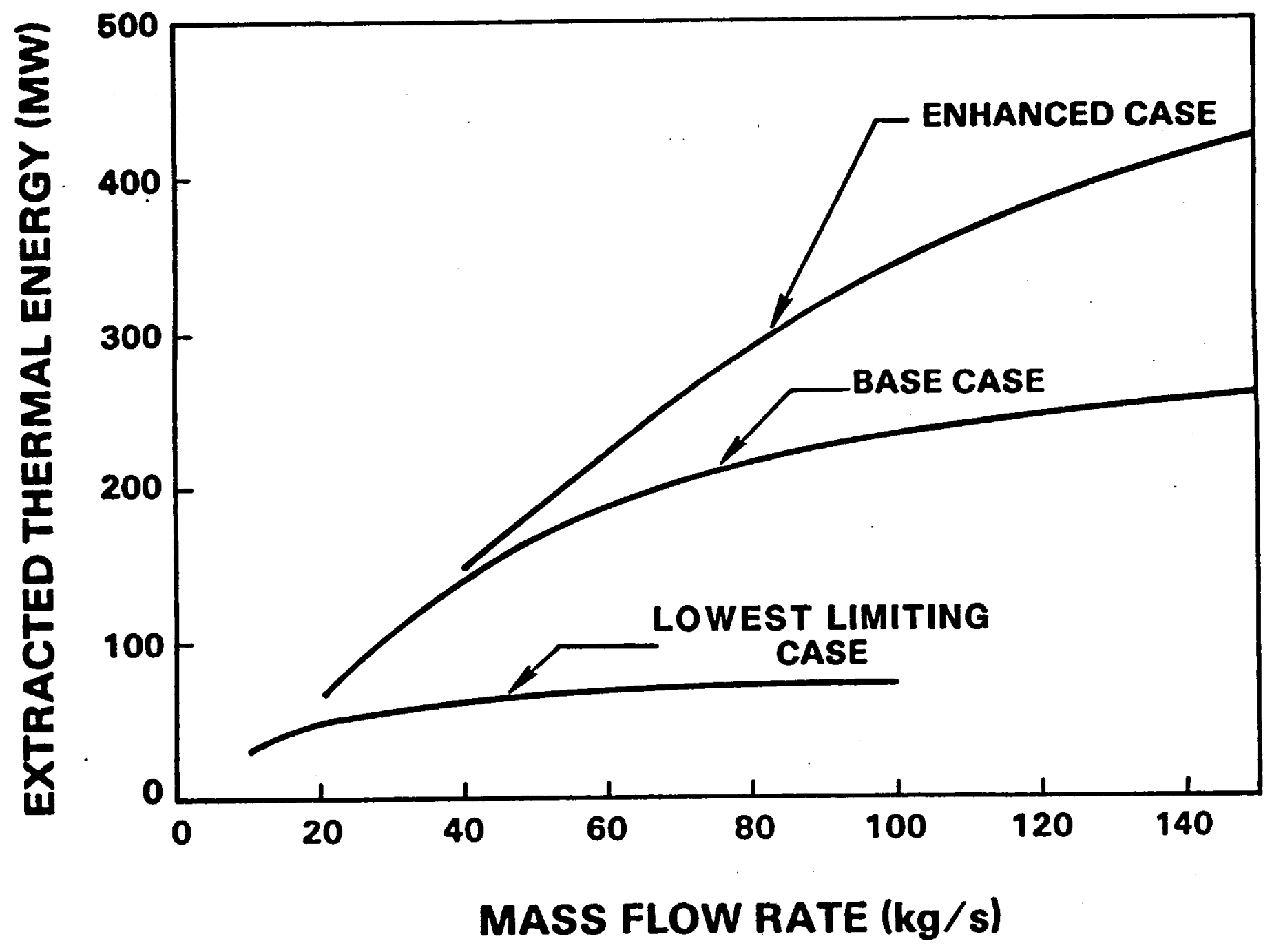

Figure 26. Extracted thermal energy vs. mass flow rate. 
important role in interconnecting the fractures. However, experiments with glass as well as the low-temperature simulant showed that the fractures do form three dimensional networks. Thus it appeared to be more useful to study thermal stress fracturing in general and to include the secondary fracture observations in future integrated energy extraction experiments. The results of low-temperature simulant thermal stress fracturing studies were reported at the GEOTHERMAL PROGRAM REVIEW VI in April 1988.

* Complete direct contact heat exchanger experiments at the University of Utah $(9 / 88)$

This milestone was completed on time. Some of the results were presented in the ASME National Heat Transfer Conference in August 1988. Further publication of results is expected in FY89.

\subsubsection{Surface Plant Activity}

The surface plant activity initially involves thermodynamic system analysis to determine potential useful work that can be converted from the energy extracted downhole. As the Magma Energy Program progresses this activity will include hardware design for energy extraction demonstration. Only tasks in thermodynamic system analysis were carried out in the present reporting period.

\section{FY88 Progress}

Thermodynamic System Analysis

Overall thermodynamic performance of conceptual systems to convert the thermal energy from a magma well to electrical energy are evaluated. In this work, three types of power plants were considered and estimated operating performance compared. These three include an open loop Rankine cycle where water from the magma well is introduced directly into the turbine; a closed loop Rankine cycle where a heat exchanger is used between the water circulating through the well and the water circulating in the power cycle; and a flashed Rankine cycle where hot liquid is throttled and then flows through a phase separator. The latter configuration is only required for cases when downhole heat exchange is poor. An open loop cycle should show the least capital investment. The closed loop cycle offers many benefits for system optimization and control of well fluid.

In the cycle analysis, an isotopic efficiency of 808 is used for both the turbine and the pump; all other irreversible losses are assumed small and negligible. The heat rejection (condenser) temperature is assumed to be $35^{\circ} \mathrm{C}$, and the expansion pressure is set equal to the saturation pressure corresponding to the heat rejection temperature. According to MAGMAXT calculations, the well is expected to be self-flowing by thermosyphoning; therefore, the reinjection pressure is set to atmospheric. In modeling the closed loop cycles, as in binary geothermal power cycle analysis (Milora and Tester, 
1976), the heat exchanger is analyzed by expressing the overall effectiveness of the heat exchanger in terms of "pinch" points, or minimum temperature differences between the two streams. A typical pinch point temperature difference of $8^{\circ} \mathrm{C}$ is used in the calculations.

The results of the closed loop cycle analysis in terms of net power output as a function of well mass flow rate is shown in Figure 27 for the three effective magma matrix thermal conductivities. These results are obtained by stepping through different operating pressures for each flow rate. The maximum power output with a turbine exit steam quality exceeding 908 is plotted. Turbine exit steam quality less than 908 is considered unrealistic. If the cycle pressure is at supercritical condition before entering the turbine, it is throttled to a subcritical pressure before expansion. The maximum power output for the base case is found to be 60 MW at a well flow rate of $65 \mathrm{~kg} / \mathrm{s}$ corresponding to a SFC (specific fluid consumption) of $3.9 \mathrm{~kg} / \mathrm{kW}-\mathrm{h}$ as compared to the typical value of $8 \mathrm{~kg} / \mathrm{kW}-\mathrm{h}$ for dry steam geothermal power plants. Sensitivity calculations are made to examine the effect of pinch point temperature difference on the net power output. These results are shown in Figure 28. The power penalty appears to vary linearly with the pinch point temperature difference. The penalty while significant is not overly severe; for example, increasing the difference from $8^{\circ} \mathrm{C}$ to $32^{\circ} \mathrm{C}$ the net power output decreases by slightly less than 108 .

A further example of the comparative results found in this study is shown in Figure 29. Here power output is shown as a function of the mass flow rate of the well for the various cycles noted above. A variety of open system expander qualities are shown to indicate performance of direct expansion devices (e.g., the total flow concept). The $80 \%$ expansion efficiency curve, which is indicative of performance of a very good axial flow steam turbine, shows data only for exit quality greater than 908. Flashed cycles did not find application in this set of results because of the relatively highquality energy exiting from the well. However, flashed cycles may have to be used in cases when the heat transfer performance is less than that assumed in Figure 26 (i.e., kmag - 15).

It appears that under the present assumption a magma well with a net power production of 25-50 MWe is entirely feasible.

\section{FY88 Milestones}

* Report initial results of thermodynamic power cycle analysis $(1 / 88)$

This milestone was completed in time. The results were presented at the ASME Winter Annual Meeting in December 1987, (Boehm, et al, 1987). 


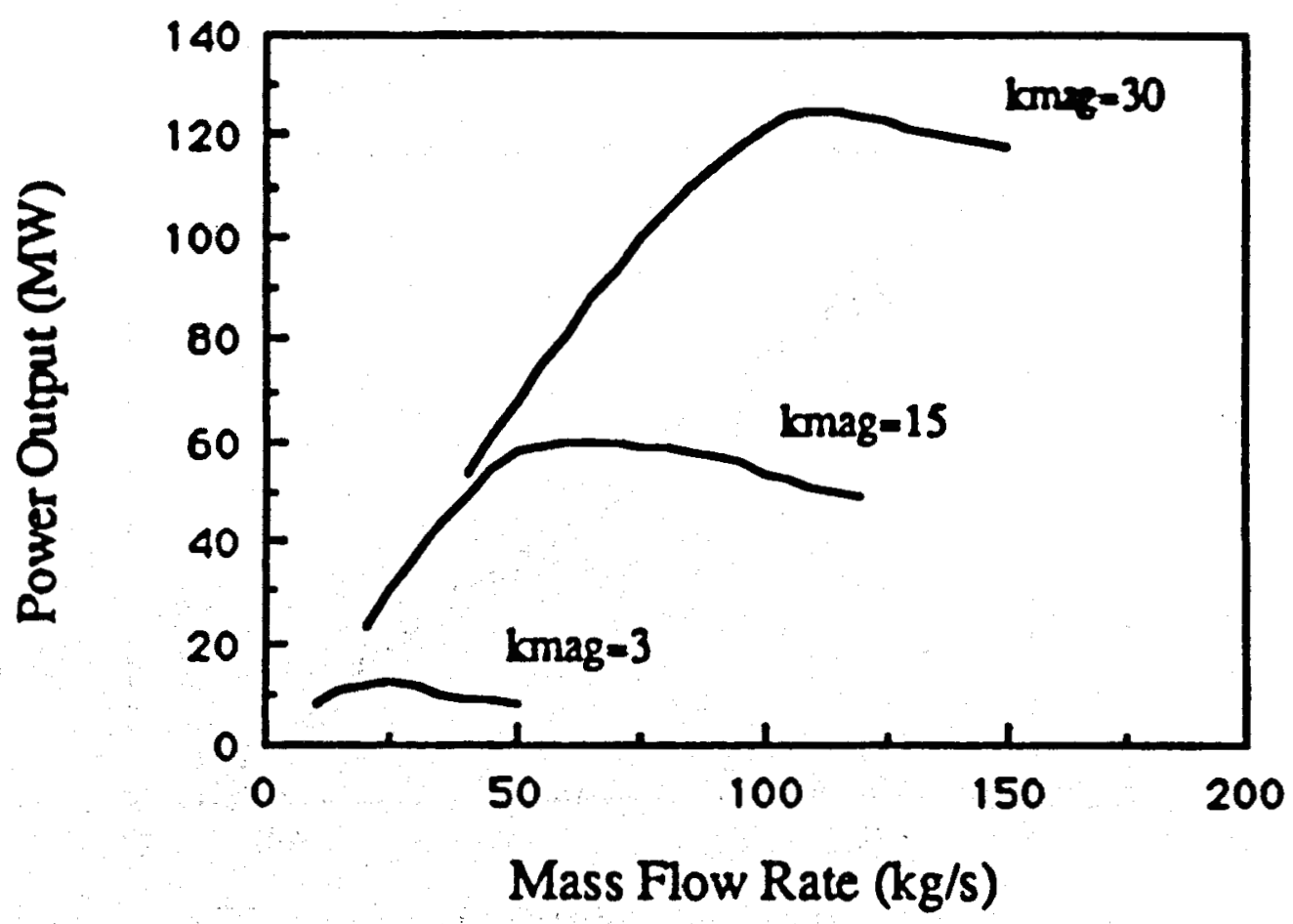

Figure 27. Calculated power output for the closed cycle. Pinch point temperature difference is $8^{\circ} \mathrm{C}$, turbine efficiency is 808 and all results have turbine exit quality of 908 or greater. ( $k_{\text {mas }}$-magma thermal conductivity, $W / m k$ ). 


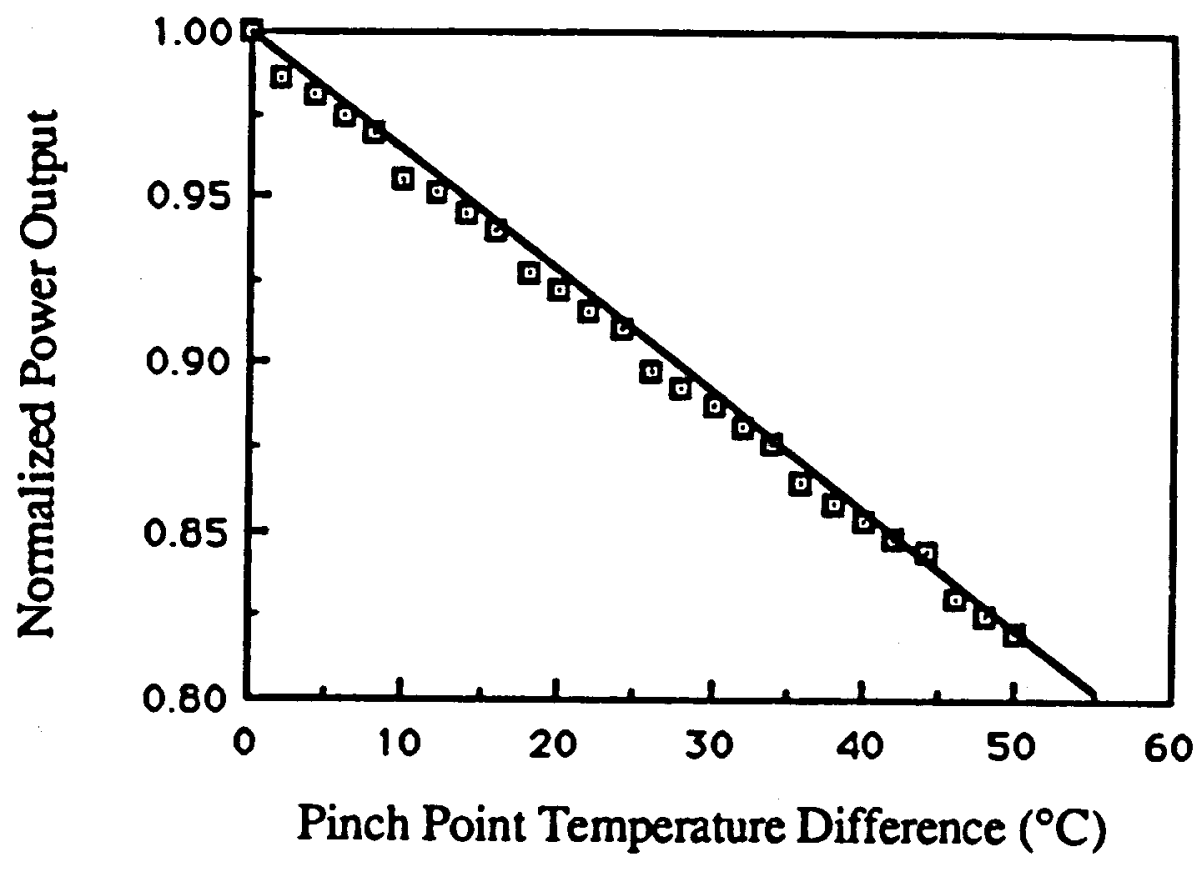

Figure 28. Calculated normalized power output vs. pinch point temperature difference. Effective magma thermal conductivity $(\mathrm{W} / \mathrm{mk})$, mass flow rate $-65 \mathrm{~kg} / \mathrm{s}$. 


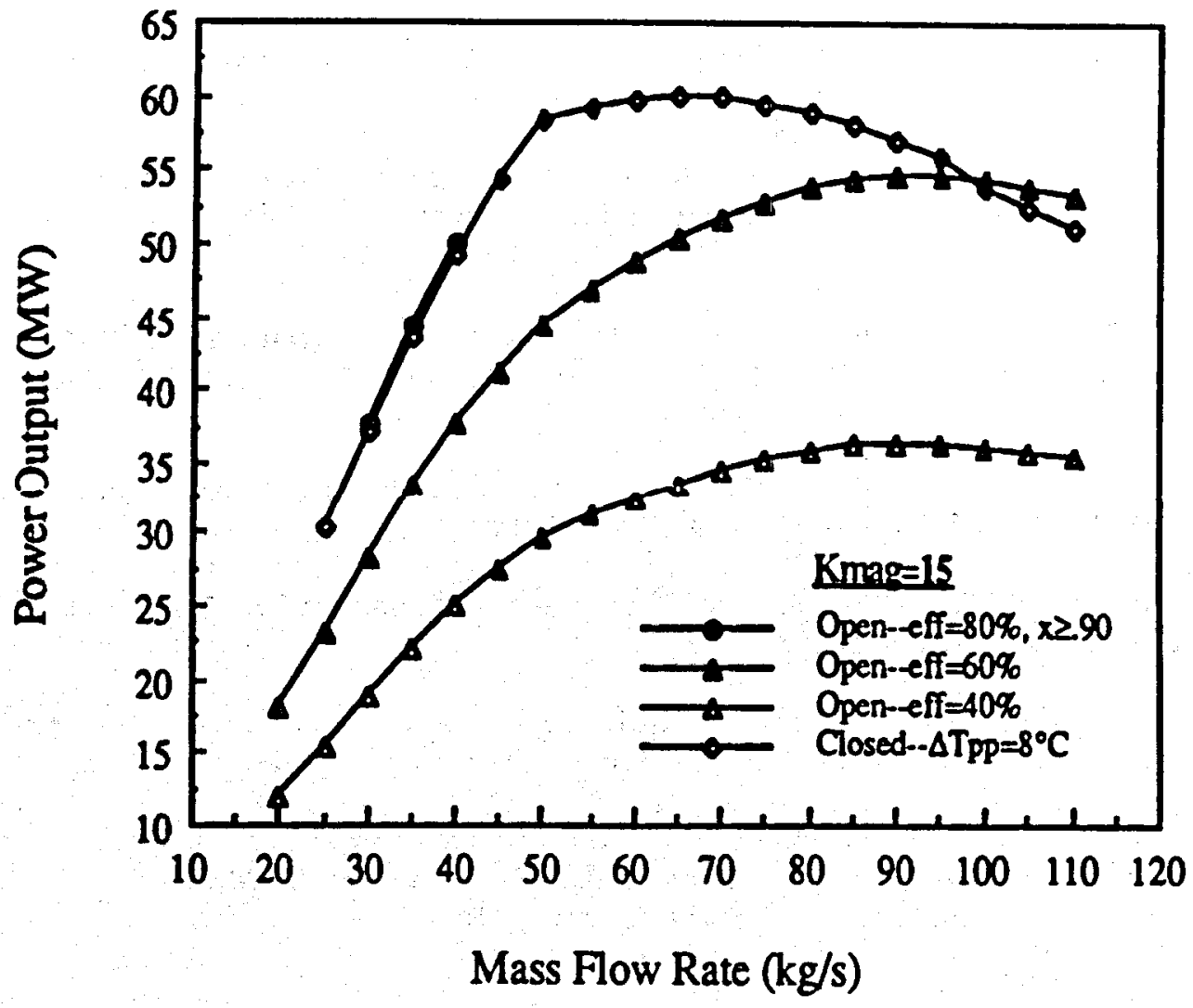

Figure 29. Summary of calculated power output as a function of mass flow rate for $\mathrm{kmag}-15$. ( $\mathrm{K}_{\text {mag }}=$ effective magma thermal conductivity, $\mathrm{W} / \mathrm{mk}$ ). 


\subsubsection{Extraction Experiment Activity}

No work was performed under this activity during the present reporting period.

\section{REFERENCES}

1. Carslaw, H. S. and C. J. Jaeger (1959), Conduction of Heat in Solids, University Press, Oxford.

2. Chu, T. Y. and C. E. Hickox (1988), "Thermal Convection with Large Viscosity Variation in an Enclosure with Localized Heating," ASME Winter annual Meeting, Chicago, December 1988.

3. Carrigan, C. R. (1987), "The Magmatic Rayleigh Number and Time Dependent Convection in Cooling Lava Lakes, GRL Vo1. 14, PP 920945.

4. Clarkson, R., N. Nwendkaema and R. Boehm (1988), "Study of Mixed Convection in a Porous Media Between Vertical Concentric Cylinders," ASME National Heat Transfer Conference, Houston, TX, August 1988.

5. FIDAP Users' Manual, Vols. 1-3, Fluid Dynamics International, 1600 Orrington Ave, Evanston, Illinois, 1987.

6. Geyer, J. T. and S. Nemat-Nasser (1982), "Experimental Investigation of Thermally Induced Cracks in Brittle Solids, " Int. J. Solids Structures, Vol 18, No. 4, pp 349-356.

7. Milora, S. L. and J. W. Tester (1976), Geothermal Energy as a Source of Electric Power - Thermodynamic and Economic Design Criteria, MIT Press, Cambridge, MA.

8. Ortega, A. (1988), "Numerical Simulation of Single Well Energy Extraction," Manuscript in Preparation.

9. Ramsey, H. J. (1962), "Wellbore Heat Transmission," J. Petr. Tech. April 1988, pp 427-435.

10. Snow, D. T. (1968), "Rock Fracture Spacings, Opening and Porosites," J. Soil. Mech. Found. Div., Proc. ASCE, 94, pp 73-91.

11. Wemple, R. P. and D. B. Longcope (1986), "Thermal Stress Fracturing of Magma Simulant Materials," SAND86-0538, Sandia National Laboratories, Albuquerque, NM. 


\subsection{MANAGEMENT}

\subsection{Organization}

Sandia Laboratories Structure:
A. Narath
D. L. Hartley
V. L. Dugan
R. W. Traeger
J. C. Dunn

President

Vice President, Energy Programs

Director, Advanced Energy Technology

Manager, GeoEnergy Technology

Supervisor, Geothermal Research

Magma Energy Extraction Management Structure:

J. C. Dunn

T. Y. Chu

R. P. Wemple

C. E. Hickox

J. T. Finger

J. B. Rundle

J. C. Eichelberger

H. R. Westrich

W. H. Casey
Supervisor, Geothermal Research

Member of Technical Staff, Energy Extraction

Member of Technical Staff, Energy Extraction

Member of Technical Staff, Energy Extraction

Member of Technical Staff, Drilling

Member of Technical Staff, Geophysics

Member of Technical Staff, Geology

Member of Technical Staff, Geochemistry

Member of Technical Staff, Geochemistry

\subsection{Inter-Agency Coordination}

The magma energy program coordinates its activities with both geothermal and geoscience groups within government agencies, national laboratories, universities, and industry. Some of the interfaces and contacts are listed below.

\section{Organization}

DOE/OBES

NSF

DOSECC

USGS

LBL

LLNL

LANL

\section{Contact}

George Kolstad

Ian MacGregor

Dan We111

Mel Friedman

Don Klick

Pat Muffler

Bob Christiansen

Dave Hill

Bill Ellsworth

Mike Sorey

H. Mahadeva Iyer

Roy Bailey

Norman Goldstein

Harold Wollenberg

Lee Younker

Paul Kasameyer

Hugh Murphy

Fraser Goff

Ken Wohletz 
BLM

USFS

CA State Geologist

CA Div. of Mines \& Geology

CA Div. of $0 i 1$ and Gas

CA Energy Commission

Mono County Board of Directors

Mono County Energy Management

City of Mammoth Lakes

New Mexico Energy and Minerals UNOCAL

Geothermal Resources Int'1

Santa Fe Geothermal

Universities

Brown

Cal Tech

SMU

Univ of Utah Research Inst.

Univ of Utah

UCSB

New Mexico Tech

Arizona State

Univ of Wisconsin
Bob Kohlbush

Jim Morrison

Mark Ziegenbein

Dean McAlister

Mark Clark

Vern McLean

Brian Tucker

Steve McNutt

Chris Higgins

Dick Thomas

Mike Smith

Andrea Lawrence

Dan Lyster

Ray windsor

Rick Schmidt

Steve Pye

Dick Dondanville

Gene Suemnicht

Jim Combs

Tim Linscott

John Arestad

Jack Hermance

Lee Silver

Hiroo Kanamori

Dave Blackwell

Dennis Nielson

Bob Boehm

Peter Malin

Alan Sanford

Jonathan Fink

Herb Wang

\subsection{Meetings}

Major meetings held during the year include:

$\begin{array}{lll}\frac{\text { Date }}{12 / 87} & \begin{array}{l}\text { Place } \\ \text { Washington }\end{array} & \begin{array}{l}\text { Purpose } \\ \text { DOE Program } \\ \text { Review }\end{array} \\ 1 / 88 & \text { Albuquerque } & \begin{array}{l}\text { Magma site } \\ \text { selection pane }\end{array} \\ 4 / 88 & \text { San Francisco } & \begin{array}{l}\text { DOE Program } \\ \text { Review VI }\end{array} \\ 6 / 88 & \text { Albuquerque } & \begin{array}{l}\text { Magma Science } \\ \text { Workshop }\end{array}\end{array}$

Results

Reviewed progress and future plans

Unanimous approval of Long Valley resurgent dome site

Presentation of progress to Industry

Developed Science Guide Outlining opportunities for scientific experiments in magma exploratory well 


\subsection{Issues}

Several key issues were resolved during the year. First selection of a drilling site on the resurgent dome was finalized and approved by a panel convened by DOE and headed by Bennie Di Bona. This allowed finalization of the permitting process and plans for drilling. Another major hurdle was resolved when BLM granted approval for drilling the deep exploratory well in Long Valley. Several meetings with local agencies and resident groups helped explain the magma energy objectives and obtain support for the permitting process.

Organization of a framework to allow add-on scientific experimentation in the exploratory well was developed. The Interagency Coordinating Group of the Continental Scientific Drilling Program agreed in principal to support measurements in this hole-ofopportunity.

\subsection{BUDGET}

\section{Project}

Long Valley Operations Drilling \& Engineering Supporting Science

Laboratory and Engineering Support Drilling Geochemistry/Materials Energy Extraction

\begin{tabular}{rrrrr} 
& \multicolumn{4}{c}{ Funding $(\mathrm{K}$ S) } \\
FY85 & FY86 & FY87 & FY88 & FY89 \\
& & & & \\
0 & 0 & 0 & 730 & 1200 \\
265 & 200 & 0 & 75 & 150 \\
& & & & \\
275 & 183 & 0 & 0 & 0 \\
448 & 425 & 250 & 200 & 100 \\
360 & 425 & 250 & 200 & 200 \\
1348 & 1233 & 500 & 1205 & 1650
\end{tabular}

TOTAL

\subsection{END-OF-YEAR STATUS}

In the Long Valley Operations task, selection of an exploratory well drill site was finalized and approved by a DOE review panel. Permits for operation at the site were initiated, and approval followed shortly after the end of the fiscal year. A magma science workshop held in Albuquerque brought together over 60 geoscientists and engineers to develop a plan for supporting scientific measurements in the magma exploratory well. Both of these events set the stage to begin Phase I drilling in Long Valley caldera during FY89. The well is planned to reach total depth during four drilling phases spanning four years. By completing a phase each year, the Level III objective for magma resource evaluation in 1992 can be met.

In the Laboratory and Engineering Support task, research continued, and progress toward long range objectives was achieved in the energy extraction and geochemistry/materials projects. Advances were made in evaluating magma convection at high Prandtl number, overall energy extraction analysis, analysis of energy conversion 
systems, understanding thermal fracturing processes, examining the reaction of potential heat exchanger materials with exsolved magmatic fluids, evaluating mass transport near the heat exchanger, and collecting laboratory data related to potential magma hazards during drilling. These accomplishments should keep the energy extraction and geochemistry/materials projects on schedule for meeting their Level III objective for drilling technology, which specifies the capability for drilling into molten magma by 1992. Funding limitations during the past three years have restricted development in the drilling area.

Several significant accomplishments during the year are highlighted below:

* Finalized site of Long Valley exploratory well

* Selected drilling engineering group for Long Valley well

* Finalized well design and initiated drilling permits

* Held Magma Science Workshop to discuss coordination of scientific measurements with engineering objectives

* Developed initial (pre-workshop) science guide for supporting scientific measurements in Long Valley well

* Completed high Prandtl number convection experiments to determine convective heat transfer rates during magma convection

* Completed direct contact heat exchanger experiments at the University of Utah

* Completed overall analysis of power production from a magma reservoir

* Measured nucleation rates for experimentally vesiculated glasses

* Measured quartz dissolution rates as a function of temperature and pressure

\subsection{FUTURE PLANS}

\subsection{Long Valley Operations}

A deep exploratory well will be drilled on the south-central part of the resurgent dome in Long Valley caldera. The location is coincident with a large number of shallow (5 to $7 \mathrm{~km}$ ) geophysical anomalies identified through many independent investigations. A staged approach to drilling is planned, with the hole reaching a depth of $20,000 \mathrm{ft}$ in a time period of four to five years. Results from the hole will permit the following:

1. Direct investigation of the geophysical anomalies interpreted to be magma. 
2. Investigation of the patterns and conditions of deep fluid circulation and heat transport below the caldera floor.

3. Determination of the amount of collapse and subsequent resurgence of the central position of Long Valley caldera.

4. Determination of the intrusion history of the central plutonic complex beneath the caldera, and establishment of the relationship of intrusive to eruptive events. Thus, the exploratory well will provide a stringent test of the hypothesis that magma is still present within the central plutonic complex.

There are two aspects to Long Valley supporting science. One is the range of scientific measurements that can be conducted in conjunction with the deep well to gain additional insight into broad topics such as caldera evolution and crustal magmatic processes. The other is more focused and is required to meet programmatic objectives or to aid the drilling process itself. The main programmatic goals are to confirm the existence of magma at drillable depths, to evaluate drilling problems, and to assess materials compatibility. These programmatic goals will be met by the magma program during drilling of the Long Valley exploratory well. Broad scientific issues that can be addressed with a deep exploratory well were identified during the Magma Science Workshop and include a wide range of measurements in four areas: (1) hydrothermal systems, (2) geophysics, (3) geology/petrology, and (4) stress and mechanics. Execution of these experiments will depend upon funding from other agencies such as DOE/OBES, NFS, and the USGS.

\subsection{Laboratory and Engineering Support}

Current objectives in energy extraction are to achieve a thorough understanding of the physical processes involved in direct magma/fluid contact heat transfer. This energy extraction concept will then be demonstrated through integrated experiments in the kilowatt range prior to final field experiments in the megawatt range. We will continue our investigation of the dynamic solidification/thermal stress fracturing phenomena as related to the operation of the direct contact heat exchanger. Experimental and numerical studies of magma convection will be concluded with recommended correlations for calculating energy extraction rates. The thermodynamic system analysis computer code and the downhole heat transfer code will be combined into a general energy extraction code. Results of the individual studies will be utilized to design a direct contact energy extraction experiment at the kilowatt level.

Our geochemistry/materials effort will continue work on hazards associated with drilling into magma. The size and number of bubbles in a rhyolite magma, that has been vesiculated in the laboratory will be measured using a digital image processing system on a SEM. This characterization will provide the kinetic data necessary for evaluating the degassing of a rhyolite magma and predicting the potential of a drilling hazard. Additional efforts will concentrate on measuring materials compatibility with volcanic gases and mass transport properties of silicate minerals in the rubble surrounding 
the heat exchanger. The compatibility study will extend current tests examining the reaction of potential heat exchanger materials with exsolved magmatic fluids to those which vary in composition from water to a concentrated brine. Experimental mass transport studies include further development of high pressure and temperature equipment to characterize and measure aluminosilicate dissolution near the heat exchanger. 
DISTRIBUTION

DOE/TIC-4500-UC-400

David N. Anderson

Geothermal Resources Council

P. 0. Box 1350

Davis, CA 95617

John Arestad

Santa Fe Geothermal

2 Galleria Tower

13455 Noel Rd., Suite 1100

Dallas, TX 75240

Roy A. Bailey

Geological Survey

345 Middlefield Rd., MS-910

Menlo Park, CA 94025

Colleen Barton

Stanford University

Department of Geophysics

Stanford, CA 94035

David Blackwe11

Southern Methodist Univ.

Dept. of Geological Sciences

Dallas, Texas 57572

Tom Blenkinsop

Institute for Crustal Studies

University of California

Santa Barbara, CA 93106

Phillip Candela

University of Maryland

Dept. of Geology

College Park, Maryland 20742

Dick Dondanville

UNOCAL

P. O. Box 6854

Santa Rosa, CA 95406

Jonathan Fink

Arizona State University

Geology Department

Tempe, AZ 85287

Mel Friedman, Dean

College of Geosciences

Texas A\&M University

College Station, TX 77843

Fraser Goff

Los Alamos National Laboratory

P. 0. Box 1663, ESS-1, MS 462

Los Alamos, NM 87545

Norman E. Goldstein

Lawrence Berkeley Laboratory

1 Cyclotron Road

Berkeley, CA 94720

Thomas L. Henyey

University of Southern

California

Dept. of Geological Sciences

Los Angeles, CA 90007

John F. Hermance

Brown University

Dept. of Geo1. Sciences

Providence, RI 02912

Robert L. Christiansen

David P. Hill

USGS

345 Middlefield Road

Menlo Park, CA 91125

U. S. Geological Survey

345 Middlefield Road, MS-977

Menlo Park, CA 94025

John L. Colp

J. L. Ivonetti

2337 Panoramic Dr.

Island Science, Inc.

Concord, CA 94520

Albuquerque, NM 87108

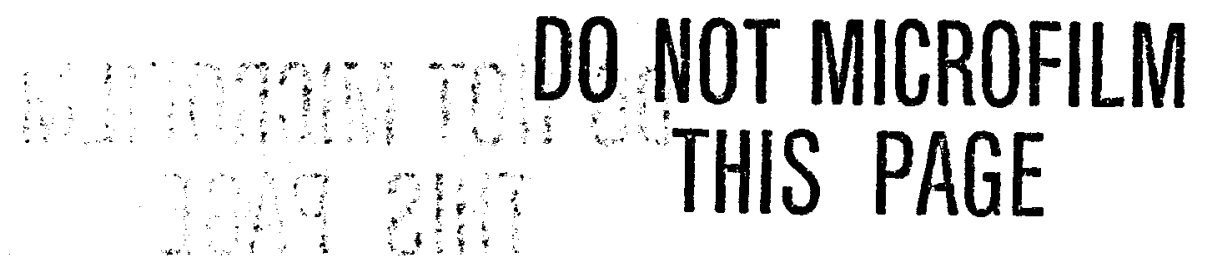


H. M. Iyer

Geological Survey

345 Middlefield Rd., MS-977

Menlo Park, CA 94025

Malcolm Johnston

Geological Survey

345 Middlefield Rd., MS-977

Menlo Park, CA 94025

Paul W. Kasameyer

Lawrence Livermore Laboratory

P. O. Box 808 , L- 224

Livermore, CA 94550

Donald W. Klick

U. S. Geological Survey

12201 Sunrise Valley Dr., MS-905

Reston, VA 22092

Schon S. Levy

Los Alamos National Laboratory

P. O. Box 1663, ESS-1, MS D462

Los Alamos, NM 87545

Bill Livesay

Livesay Consultants

2616 Angell Ave.

San Diego, CA 92122

Willian C. Lyons

New Mexico Tech.

Petroleum Enginering Dept.

Socorro, NM 87801

Danie1 L. Lyster

Mono County Energy Mgmt.

P. 0. Box 8060

Mammoth Lakes, CA 93546

Car1 E. Mortensen

Geological Survey

345 Middlefield Rd., MS-977

Menlo Park, CA 94025

Dennis Nielson

University of Utah Research Institute

391 Chipeta Way, Suite C

Salt Lake City, Utah 84108
Brennan 0'Neill

Geological Survey

345 Middlefield Rd., MS-977

Menlo Park, CA 94025

J. J. Papike

South Dakota School of Mines and Technology

501 E. St. Joseph Street

Rapid City, SD 57701-3995

William A. Prothero, Jr. University of California

Department of Geological Sciences

Santa Barbara, CA 93106

Christopher 0. Sanders

Geological Survey

345 Middlefield Rd, MS -977

Menlo Park, CA 94025

John H. Sass

Geological Survey

2255 North Gemini Drive

Flagstaff, AZ 86001

L. T. Silver

Division of Geological and

Planetary Sciences

California Institute of Technology

Pasadena, CA 91125

Michael L. Sorey

Geological Survey

345 Middlefield Rd, MS-439

Menlo Park, CA 94025

U. S. Department of Energy (4)

Geothermal Technologies Div.

Attn: Marshall Reed

Ted Mock

Alan Jelacic

Gladys Hooper

Forrestal B1dg., CE-324

1000 Independence Ave., SW

Washington, DC 20585

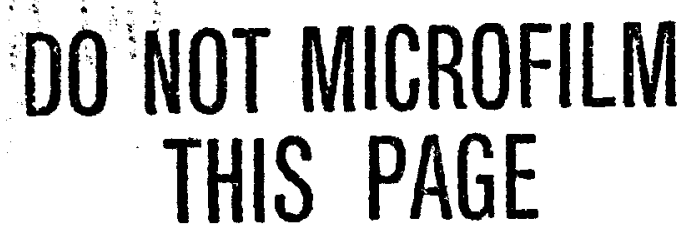


U. S. Department of Energy Office of Basic Energy Sciences Attn: George A. Kolstad Mail Stop J-309

Washington, DC 20585

Herbert F. Wang

University of Wisconsin

Lewis G. Weeks Hall

1215 W. Dayton St.

Madison, Wisconsin 53706

K. H. Wohletz

Los Alamos National Laboratory

P. 0. BoX 1663, ESS-1, MS D-4

Los Alamos, NM 87545

H. A. Wollenberg

Lawrence Berkeley Laboratory

1 Cyclotron Road

Berkeley, CA 94720

Mike Wright

Earth Science Laboratory

Univ. of Utah Research Inst.

391 Chipeta Way, Ste. A

Salt Lake City, UT 84108

Leland W. Younker

Lawrence Livermore Laboratory

P. 0. Box $808, \mathrm{~L}-224$

Livermore, CA 94550

Mark Ziegenbein

BLM, Suite 201

$873 \mathrm{~N}$. Main St.

Bishop, CA 93514
1513

3141

3151

3154-1

6200

6230

6231

6231

6231

6233

6233

6233

6233

6250

6252

6252

6252

6252

8524
C. E. Hickox

S. A. Landenberger (5)

W. I. Klein (3)

C. L. Ward (8) for DOE/OSTI

V. L. Dugan

W. C. Luth

H. C. Hardee

J. B. Rundle

C. R. Carrigan

T. M. Gerlach

H. R. Westrich

J. C. Eichelberger

W. H. Casey

R. K. Traeger

J. C. Dunn (15)

T. Y. Chu

J. T. Finger

R. P. Wemple

J. R. Wackerly

\section{DO NOT MICROFILM THIS PAGE}

